\title{
Microglia Enhance Neurogenesis and Oligodendrogenesis in the Early Postnatal Subventricular Zone
}

\author{
Yukari Shigemoto-Mogami, ${ }_{1}^{1}$ Kazue Hoshikawa, ${ }^{1}$ James E. Goldman, ${ }^{2}$ Yuko Sekino, ${ }^{1}$ and Kaoru Sato ${ }^{1}$ \\ ${ }^{1}$ Laboratory of Neuropharmacology, Division of Pharmacology, National Institute of Health Sciences, Tokyo 158-8501, Japan, and ${ }^{2}$ Department of \\ Pathology and Cell Biology, Columbia University College of Physicians and Surgeons, New York, New York 10032
}

\begin{abstract}
Although microglia have long been considered as brain resident immune cells, increasing evidence suggests that they also have physiological roles in the development of the normal CNS. In this study, we found large numbers of activated microglia in the forebrain subventricular zone (SVZ) of the rat from P1 to P10. Pharmacological suppression of the activation, which produces a decrease in levels of a number of proinflammatory cytokines (i.e., IL-1 $\beta$, IL-6, TNF- $\alpha$, and IFN- $\gamma$ ) significantly inhibited neurogenesis and oligodendrogenesis in the SVZ. In vitro neurosphere assays reproduced the enhancement of neurogenesis and oligodendrogenesis by activated microglia and showed that the cytokines revealed the effects complementarily. These results suggest that activated microglia accumulate in the early postnatal SVZ and that they enhance neurogenesis and oligodendrogenesis via released cytokines.
\end{abstract}

Key words: cytokine; microglia; neurogenesis; neurosphere; oligodendrogenesis; subventricular zone

\section{Introduction}

CNS microglia have long been considered as resident immune cells, which are activated in response to pathological events. In pathological conditions, they change their morphology to an amoeboid shape, acquiring activation-specific phenotypes, such as chemotaxis, phagocytosis, and secretion of inflammatory cytokines (Nakajima and Kohsaka, 2001; Inoue, 2008; Monji et al., 2009; Kettenmann et al., 2011). However, microglia also have physiological roles in the normal CNS. They actively survey their territory with fine processes and receive stimuli from the environment as sensor cells (Kettenmann et al., 2011). In vivo lineage tracing studies have established that microglia differentiate from primitive myeloid progenitors that arise before embryonic day 8 and are identified in the CNS parenchyma even before definitive hematopoiesis (Ginhoux et al., 2010), whereas it has also been shown that microglia migrate from the lateral ventricle into the brain via the subventricular zone (SVZ) in the postnatal brain (Mohri et al., 2003). In the early embryonic brain, most microglia adopt an amoeboid morphology and characteristics of an activated form (Hirasawa et al., 2005). Microglia in the embryonic

Received April 15, 2013; revised Dec. 21, 2013; accepted Dec. 27, 2013.

Author contributions: K.S. designed research; Y.S.-M., K.H., and K.S. performed research; Y.S.-M., K.H., J.E.G. Y.S., and K.S. analyzed data; Y.S.-M., J.E.G., Y.S., and K.S. wrote the paper.

This work was supported in part by a Grant-in-Aid for Young Scientists from MEXT, Japan (KAKENHI 21700422), the Program for Promotion of Fundamental Studies in Health Sciences of NIBIO, Japan, a Health and Labor Science Research Grant for Research on Risks of Chemicals, a Labor Science Research Grant for Research on New Drug Development from the MHLW, Japan to K.S., and a Health and Labor Science Research Grant for Research on Publicly Essential Drugs and Medical Devices, Japan to Y.S.

The authors declare no competing financial interests.

This article is freely available online through the J Neurosci Author Open Choice option.

Correspondence should be addressed to Dr. Kaoru Sato, Laboratory of Neuropharmacology, Division of Pharmacology, National Institute of Health Sciences, Kamiyoga 1-18-1, Setagaya-ku, Tokyo 158-8501, Japan. E-mail: kasato@nihs.go.jp.

DOI:10.1523/JNEUROSCI.1619-13.2014

Copyright $\odot 2014$ the authors $\quad 0270-6474 / 14 / 342231-13 \$ 15.00 / 0$
SVZ limit the production of cortical neurons by phagocytosing neural precursor cells (Cunningham et al., 2013). The number of microglia in the brain reaches a maximum during the early postnatal weeks (Wu et al., 1993; Xu and Ling, 1994), after which they transform into cells with a ramified shape, the typical morphology observed in the adult CNS (Ignácio et al., 2005). However, microglia are densely populated in neurogenic niches, such as the SVZ (Mosher et al., 2012), and appear more activated in the adult SVZ than in non-neurogenic zones (Goings et al., 2006). These developmental changes in the activation and the distribution of microglia strongly suggest that microglia play important roles in CNS development. However, the developmental dynamics of microglia in the postnatal SVZ and their roles in neurogenesis and gliogenesis at this stage are not well understood. We have examined the distribution and morphology of microglia in the rat forebrain during the neonatal-early postnatal period in detail and found a large number of active forms within the SVZ from P1 to $\mathrm{P} 10$, which then transformed from an activated form to a ramified form after P14. We here present evidence that microglia in the early postnatal SVZ promote both neurogenesis and oligodendrogenesis and that cytokines are important in these effects. To our knowledge, this is the first report showing a novel physiological function of microglia regulating neurogenesis and oligodendrogenesis in the early postnatal brain.

\section{Materials and Methods}

Animals and treatment. All animals were treated in accordance with the guidelines for the Care and Use of Laboratory Animals of the Animal Research Committee of the National Institute of Health Sciences and followed the Guide for the Care and Use of Laboratory Animals. All experiments were approved by the Animal Research Committee of National Institute of Health Sciences and conformed to the relevant regulatory standards. The Wistar rats were purchased from Japan SLC and maintained under specific pathogen-free conditions at a controlled temperature and humidity and on a $12 \mathrm{~h} \mathrm{light} / 12 \mathrm{~h}$ dark cycle and had ad libitum 

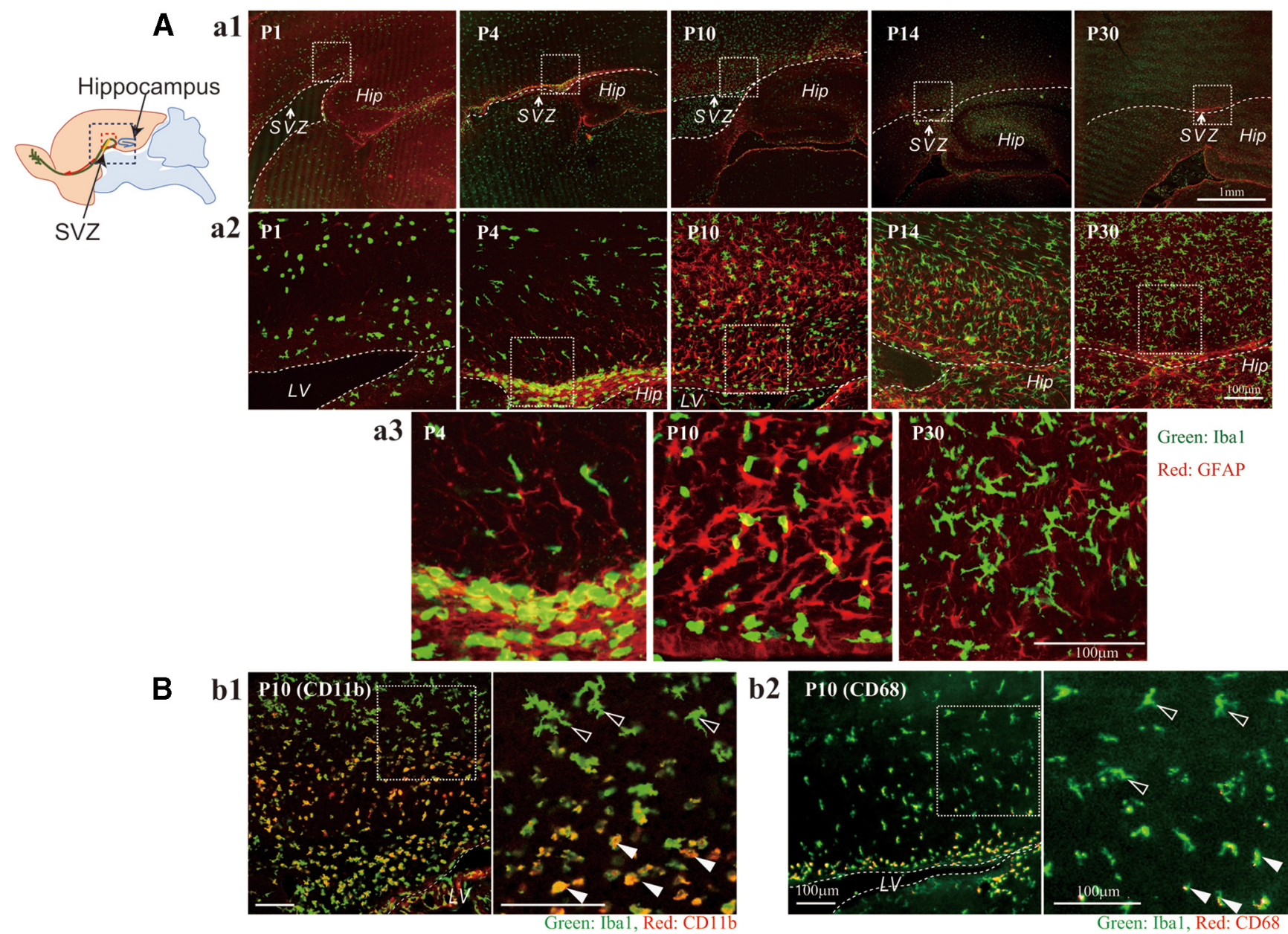

Figure 1. There is a population of activated microglia accumulated in the early postnatal SVZ. Aa1, Distribution of microglia in the postnatal VZ/SVZ (P1, P4, P10, P14, P30). Sagittal sections of forebrains were immunostained with anti-lba1 (green: microglia) and anti-GFAP antibodies (red: neural stem cells and astrocytes). Aa2, Magnified images of the hatched squares in Aa1. The accumulation in the SVZ in P4 and P10 was distinctive. Aa3, Magnified images of the hatched squares in Aa2. Morphological changes of microglia with age from amoeboid shape to more ramified shape is remarkable (P4, P10, P30). Bb1, Activation of microglia in P10 SVZ. Sagittal sections immunostained with anti-CD11b (red: activated microglia) and anti-lba1 antibodies (green: microglia). Right panel, Magnified image of the hatched square in the left panel. The microglia in the SVZ have an amoeboid shape and positive for CD11b (white arrowheads), whereas those outside SVZ have more ramified shape and are negative for CD11b (black arrowheads). Bb2, Sagittal sections immunostained with anti-CD68 (red: activated microglia) and anti-lba1 antibodies (green: microglia). Right panel, Magnified image of the hatched square in the left panel. The microglia in the SVZ have an amoeboid shape and positive for CD68 (white arrowheads), whereas those outside SVZ have more ramified shape and are negative for CD68 (black arrowheads). Similar results were obtained in three independent experiments.

access to food and water. Minocycline $(30 \mathrm{mg} / \mathrm{kg})$ or the same volume of PBS was injected into rats of either sex intraperitoneally for $3 \mathrm{~d}$ from postnatal day 2 (P2). Six hours after the last injection, rats were deeply anesthetized and the brains were removed on ice.

Immunohistochemistry (sagittal sections). Rats ( $\mathrm{P} 1, \mathrm{P} 4, \mathrm{P} 10, \mathrm{P} 14, \mathrm{P} 30)$ were anesthetized and then perfused with saline followed by $4 \% \mathrm{PFA}$, and then the brains were removed. From each half brain, sagittal sections were cut laterally at a thickness of $30 \mu \mathrm{m}$ beginning $2 \mathrm{~mm}$ lateral from the midline. The sections were incubated for $2 \mathrm{~h}$ at room temperature in a blocking solution (3\% normal goat serum, $0.3 \%$ Triton X-100 in PBS) and incubated for $24 \mathrm{~h}$ at $4{ }^{\circ} \mathrm{C}$ in the solution, including the primary antibodies (rabbit anti-Ibal antibody [019-9741, Wako; 1:500], mouse anti-GFAP antibody [MAB3402, Millipore; 1:200], mouse anti-rat CD11b antibody [MAB1405, AbD Serotec; 1:100], anti-rat CD68 antibody [MCA341R, AbD Serotec; 1:100], rabbit anti-Ki-67 [SP6, M3061, Spring Bioscience; 1:10], anti-nestin antibody [MAB353, Millipore; 1:100], goat anti-doublecortin [Dcx] antibody [sc-8066, Santa Cruz Biotechnology; 1:200], goat anti-PDGFR $\alpha$ antibody [sc-31178, Santa Cruz Biotechnology; 1:50], anti-oligodendrocyte marker O1 [O1] antibody [MAB344, Millipore, 1:50], mouse anti-MBP antibody [MAB 382, Millipore; 1:50], rabbit anti-ALDH1L1 antibody-astrocyte marker antibody [ab87117, Abcam; 1:1000], mouse anti-S100 $\beta$ antibody [S2532, Sigma; 1:100], rabbit anti IGF-1 antiserum [GroPep Biotechnology; [1:200]).
After incubation, the sections were washed and incubated for $3 \mathrm{~h}$ at room temperature in the solution, including the secondary antibodies (anti-rabbit IgG-conjugated Alexa Fluorochrome or anti-mouse IgGconjugated Alexa Fluorochrome [Invitrogen; 1:1000]). The stained sections were analyzed using a Nikon A1R-A1 confocal microscope system. To count the number of cells positive for each differentiation marker, $613 \times 613 \mu \mathrm{m}^{2}$ and $1024 \times 1024 \mu \mathrm{m}^{2}$ squares were set on both sides of the fornix. The cell numbers in the two squares were counted and averaged for the cell numbers in one section. The averaged data of 3 sections at $90 \mu \mathrm{m}$ intervals were treated as the data of one animal and the data from 6 animals were statistically analyzed.

Immunohistochemistry (coronal sections). Three points on the skull at three different rostrocaudal stereotaxic coordinates (i.e., anterior, middle, posterior) were marked with animal tattoo ink (Ketchum) at P1. These three points with different rostrocaudal levels were determined according to a previous report (Suzuki and Goldman, 2003): rostral point: $2 \mathrm{~mm}$ anterior, $1 \mathrm{~mm}$ lateral to the bregma; middle point: $0.7 \mathrm{~mm}$ anterior, $1 \mathrm{~mm}$ lateral to the bregma; caudal point: $0.5 \mathrm{~mm}$ posterior, 1 $\mathrm{mm}$ lateral to the bregma. Then the animals were perfused at P1, P3, P10, and P30, and the brains were removed as described above. From each half brain, coronal sections were cut at each marked point from anterior to posterior. The sections were immunostained with anti-Ibal and antiCD68 as described above. After immunostaining, the sections were coun- 
A

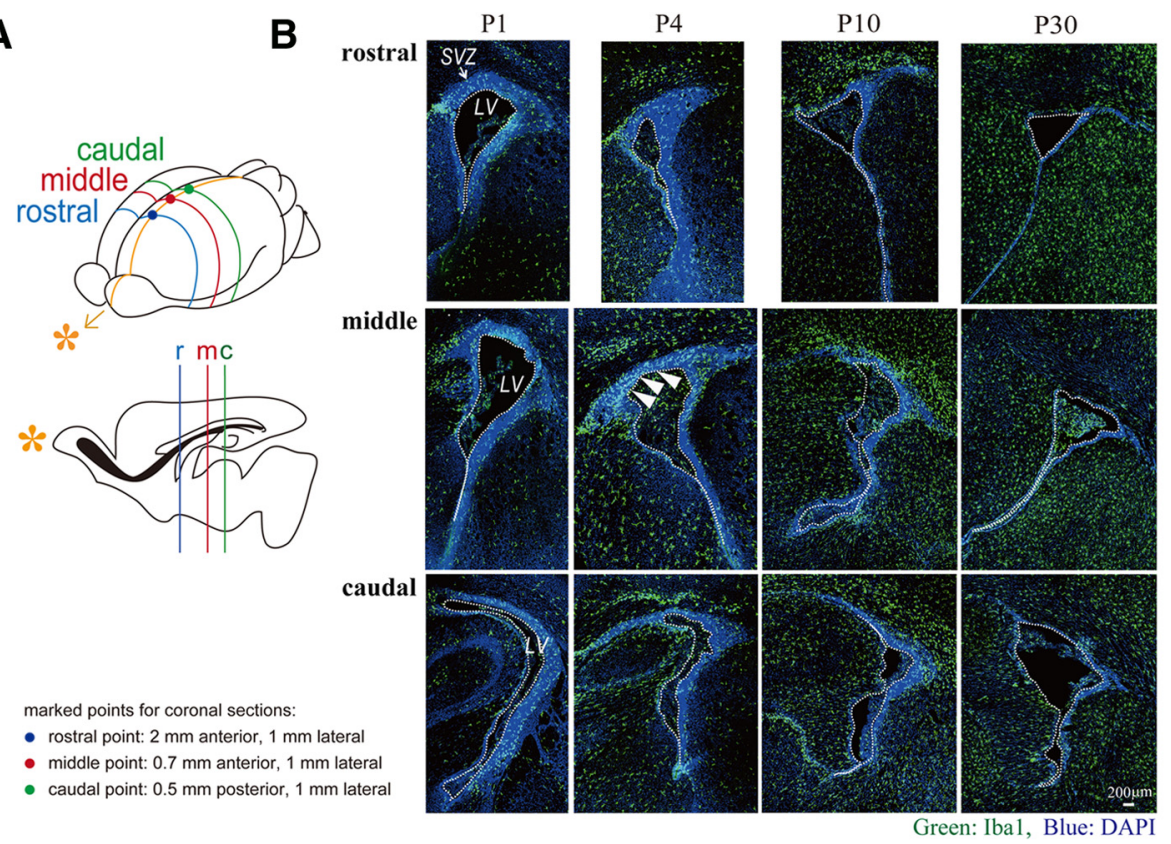

C P1 P4 P10 P30
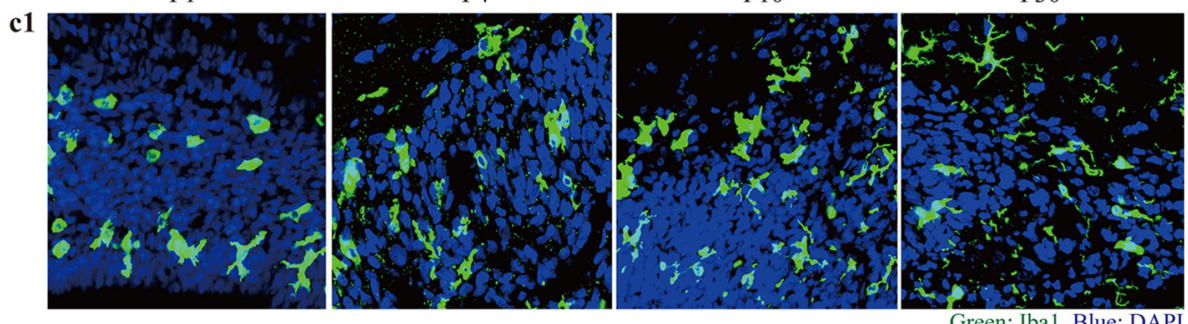

c2
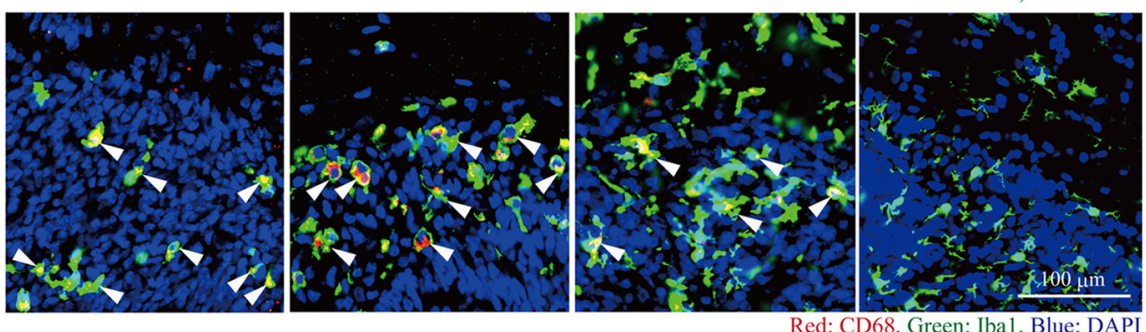

D
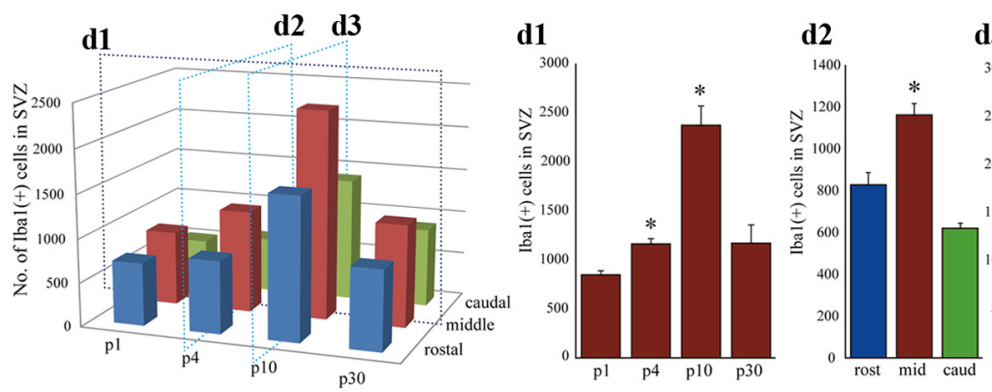

d3

E

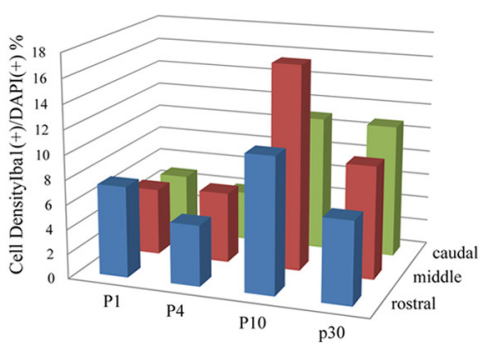

F

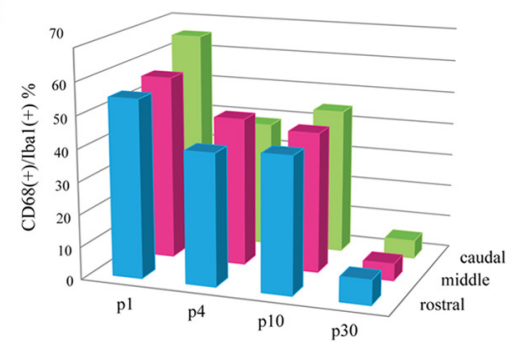


terstained with DAPI (1:500; Invitrogen) for $30 \mathrm{~min}$ to visualize the SVZ. The cell numbers of microglia $\left(\mathrm{Ibal}^{+}\right)$and activated microglia ( $\mathrm{Ibal}^{+}$ $\mathrm{CD}^{+} 8^{+}$) in the SVZ (the region with dense DAPI signals) were counted in one section. The averaged data of three sections at $90 \mu \mathrm{m}$ intervals across the marked points were treated as the data for each rostrocaudal level. The data from 6 to 9 hemispheres per one rostrocaudal level were statistically analyzed.

Western blotting. P4 Wistar rat brains were cut into sagittal sections. Under a microscope, a parasagittal section (from $1 \mathrm{~mm}$ lateral, $2 \mathrm{~mm}$ thickness) was taken from each half brain and meninges were carefully removed. The VZ/SVZ was identified by its slightly darker, more transparent appearance compared with the overlying corpus callosum. We cut out the VZ/SVZ between $0.4 \mathrm{~mm}$ anterior and $3 \mathrm{~mm}$ posterior (posterior end of SVZ) from bregma so as not to include the rostral migratory stream. Dissected VZ/SVZ tissues were homogenized on ice in extraction buffer ( 20 mм Tris, 2 mм EDTA, 0.5 mм EGTA, 0.32 м sucrose, protease inhibitor mixture), and centrifuged at $1000 \times g$ for $10 \mathrm{~min}$. Proteins in the lysates were resolved with SDS-PAGE and transferred to PVDF membranes. The membranes were incubated overnight in BlockAce blocking solution at $4^{\circ} \mathrm{C}$. Then the membranes were incubated with primary antibodies (anti-CD11b [1:1000], anti-CD68 [1:2000], anti-nestin [1: 1000], anti-PDGFR $\alpha$ [1:200], anti-ALDH1L1 [1:1000], anti-S100 $\beta$ [1: 2000]) for $1 \mathrm{~h}$ at $25^{\circ} \mathrm{C}$. After washing three times, the membranes were incubated with HRP-conjugated anti-rabbit or anti-mouse antibody (1:5000) for $1 \mathrm{~h}$ at $25^{\circ} \mathrm{C}$. The membranes were then washed three times and signals were visualized by chemiluminescence detectors LAS3000 (Fuji film).

Measurement of cytokine levels. Cytokine levels in the SVZ were determined with Bio-Plex cytokine analysis system (Bio-Rad Laboratories). Tissue lysates of VZ/SVZ fractions were obtained from rats at P1, P4, P10, and P30 as described in Western blotting. The concentrations of Il- $1 \alpha$, Il-1 $\beta$, IL-2, IL-4, IL-6, Il-10, GM-CSF, IFN- $\gamma$, and TNF- $\alpha$ were measured by the Bio-Plex rat cytokine 9 plex kit according to the manufacturer's instruction. In some cases, IGF-1, Il- $1 \beta$ IL-6, TNF- $\alpha$, and IFN- $\gamma$ concentrations were measured by ELISA kit according to the manufacturer's instruction. The protein levels of tissue lysates were measured by BCA protein assay. The amount of each cytokine in $100 \mu \mathrm{g}$ of total protein is shown for comparison. To determine the cytokine release from activated microglia in vitro, microglia were activated by LPS $(10 \mathrm{ng} / \mathrm{ml})$ in the presence or absence of minocycline $(10 \mu \mathrm{M})$ for $30 \mathrm{~min}$ and washed carefully and incubated in the normal medium for $24 \mathrm{~h}$. After $24 \mathrm{~h}$ incubation, the cell culture supernatants were collected, and concentration of Il-1 $\beta$, IL-6, IFN- $\gamma$, and TNF- $\alpha$ were measured by ELISA kit.

Cell culture: neurosphere culture. Rat neural stem cells were cultured as previously described (Reynolds et al., 1992; Hamanoue et al., 2009) with slight modifications. Briefly, telencephalons were dissected from embry-

\section{$\leftarrow$}

Figure 2. The temporal and spatial dynamics of activated microglia in the postnatal SVZ. A, A schematic of the rostrocaudal levels in this experiment. $\boldsymbol{B}$, The distribution of microglia in the rostral, medial, and caudal SVZ at P1, P4, P10, and P30. Coronal sections of forebrains at rostral ( $2 \mathrm{~mm}$ anterior to the bregma), medial ( $0.7 \mathrm{~mm}$ anterior to the bregma), and caudal $(0.5 \mathrm{~mm}$ posterior to the bregma) levels were immunostained with anti-lba1 (green: microglia) followed by DAPI staining (blue: cell nuclei). A population of activated microglia accumulated within the SVZ at P1-P10. Cc1, Typical morphology of microglia in the middle SVZ at P1, P4, P10, and P30. Morphological change of microglia with age from amoeboid shape to more ramified shape is remarkable. Cc2, The middle SVZ sections immunostained with anti-CD68 (red: activated microglia) and anti-lba1 antibodies (green: microglia). The microglia at P1, P4, and P10 in the SVZ have an amoeboid shape and are positive for CD68 (representative cells: white arrowheads), whereas those at $p 30$ have a more ramified shape and are negative for $C D 68$. D, The quantification of the number of $\mathrm{Iba} 1^{+}$cells in the SVZ. $\mathbf{d 1}$, Time course of the $\mathrm{Iba} 1^{+}$microglia in the middle SVZ. The number peaked at P10. d2, d3, The comparison of the numbers of microglia among the rostral, middle, and caudal SVZ at P4 (d2) and P10 (d3). ${ }^{*} p<0.05$ versus $p 1$ or rost group (Tukey's test by ANOVA). Data are mean \pm SEM. $E$, The cell density of Iba ${ }^{+}$microglia at different rostrocaudal levels at P1, P4,P10, and P30. The cell density of microglia in the SVZ paralleled with that of the number of microglia throughout a period of the observation. $\boldsymbol{F}$, The ratio of activated microglia in the $\mathrm{SVZ}\left(\mathrm{CD} 8^{+} / \mathrm{lba1}{ }^{+}\right)$. During the experimental period, the highestratio was obtained at P1. We confirmed the similar results in three independent experiments. onic day 16 (E16) rats of either sex in ice-cold DMEM/F12, minced, and dispersed into single cells by pipetting. Cells were then cultured in DMEM/F12 containing B27 supplement $(\times 200), 20 \mathrm{ng} / \mathrm{ml} \mathrm{FGF2}$, and 20 $\mathrm{ng} / \mathrm{ml} \mathrm{EGF}$ for $7 \mathrm{~d}$. The primary neurospheres and single cells were differentiated in growth factor-free medium in glass chambers coated with ornithine/fibronectin. In some cases, primary neurosphere were incubated with TrypLE Select for $15 \mathrm{~min}$ and dissociated by pipetting. Single cells were differentiated in glass chambers coated with polyornithine/laminin.

Microglia culture. Rat microglia were cultured as previously described (Nakajima et al., 1992). In brief, mixed glial cultures were prepared from the cerebral cortex of P1 Wistar rats and maintained for 12-23 d in DMEM containing 10\% FBS. The floating microglia over the mixed glial cultures were collected and transferred to appropriate dishes or transwells.

Neural stem cell differentiation assay. To examine the effects of activated microglia on neural development and the contribution of cytokines to the effects, we used modified cocultures of neurospheres with activated microglia. Microglia cultured independently of neurospheres on transwells were activated by LPS $(10 \mathrm{ng} / \mathrm{ml})$ in the presence or absence of minocycline $(10 \mu \mathrm{M})$ for $30 \mathrm{~min}$ and washed carefully to prevent residual LPS and minocycline. The transwells on which microglia were cultured were set on the neurospheres $1 \mathrm{~d}$ after the starting point of the differentiation and incubated for differentiation periods suitable for neurons $(7 \mathrm{~d}$ ) or oligodendrocytes $(11 \mathrm{~d})$. In some cases, we performed the coculture of cells dissociated from neurospheres and activated microglia. To check the effects of minocycline alone, these cells were incubated in the presence of minocycline $(10 \mu \mathrm{M})$ for $7 \mathrm{~d}$. Neurospheres and single neural stem cells were immunohistochemically stained for $\beta 3$-tubulin, PDGFR $\alpha$, O4, GFAP, and TOTO3 according to the manufacture's instruction (Stem Cell Kits, R\&D Systems). To examine the effects of function-blocking antibodies on differentiation, the neurospheres were differentiated in the presence of function-blocking antibodies (goat anti-rat IL-1 $\beta$ antibody [AF-501-NA, R\&D Systems], goat anti-rat IL-6 antibody [AF-506, R\&D Systems], TNF- $\alpha$ antibody [70R-TR007X, Fitzgerald], and goat anti-mouse/rat IFN- $\gamma$ antibody [AF-585-NA, R\&D Systems]) (1 $\mu \mathrm{g} / \mathrm{ml}$ for each). The effects of these function-blocking antibodies were compared with the same concentration of isotypematched control IgG: normal goat IgG control [AB-108-C, R\&D Systems] and rabbit IgG control [31R-AR001, R\&D Systems] ( $1 \mu \mathrm{g} / \mathrm{ml}$ for each). The effect of the mixture of function blocking antibodies (goat anti-rat IL- $1 \beta$ antibody, goat anti-rat IL- 6 antibody, TNF- $\alpha$ antibody, and goat anti-mouse/rat IFN- $\gamma$ antibody, $1 \mu \mathrm{g} / \mathrm{ml}$ for each) was compared with the control, which included same concentrations of isotypematched control IgGs (i.e., $3 \mu \mathrm{g} / \mathrm{ml}$ of normal goat IgG control and 1 $\mu \mathrm{g} / \mathrm{ml}$ of rabbit IgG control). To examine the effects of a single cytokine, the neurospheres were differentiated in the presence of each individual recombinant cytokine (rIL-1 $\beta$, rIL-6, rTNF- $\alpha$, and rIFN- $\gamma$ at 1 or 10 $\mathrm{ng} / \mathrm{ml}$ ). After the differentiation period, the cells were stained immunocytochemically as described above.

Data analysis and statistics. All data are shown as the mean \pm SEM. Statistical analysis was performed using Student's $t$ test, or Tukey's test by ANOVA. Differences were considered to be significant at $p<0.05$.

Materials. Minocycline, LPS, anti-S100 $\beta$ antibody (S2532), and EGF were purchased from Sigma. Bio-Plex rat cytokine 9 plex was purchased from Bio-Rad Laboratories. Recombinant cytokines (rIL-1 $\beta$, rIL-4, rIL-6, rIFN- $\gamma$, rTNF- $\alpha$ ) and FGF2 were purchased from PeproTech. Maximum sensitivity substrate and BCA protein assay were purchased from Thermo Scientific. CanGet Signals was purchased from Toyobo. HRP-conjugated anti-rabbit, mouse antibodies were purchased from GE Healthcare Life Science. DAPI, TOTO3, anti-mouse, sheep, rabbit IgG, and anti-mouse IgM-conjugated AlexaFluor were purchased from Invitrogen. BlockAce was purchased from DS Pharma Biomedical. B27 supplement, TrypLE Serect, FBS, and DMEM were purchased from Invitrogen.

\section{Results}

We first investigated the distribution of microglia in the postnatal rat forebrain (Figs. 1 and 2). Sagittal sections were immuno- 
A
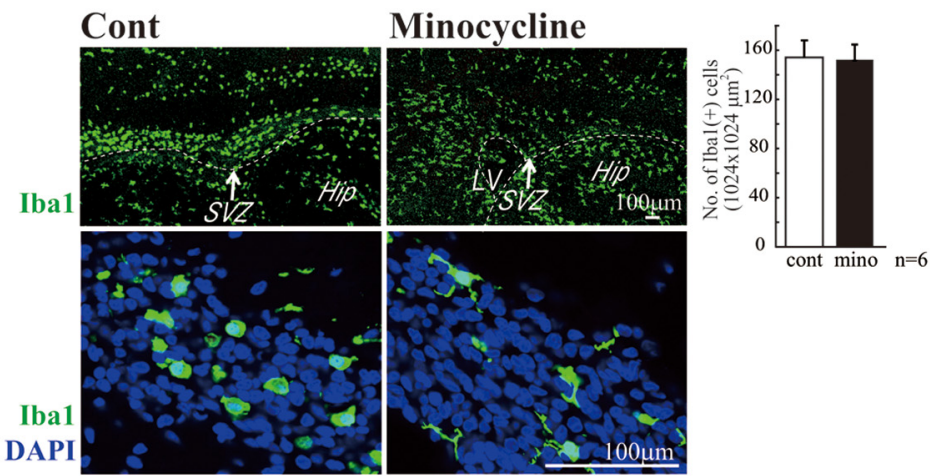

B

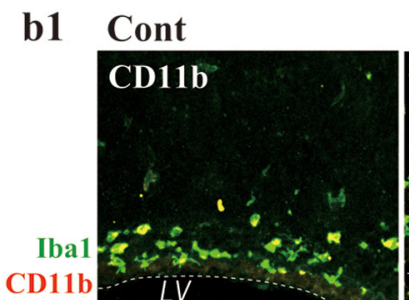

Minocycline
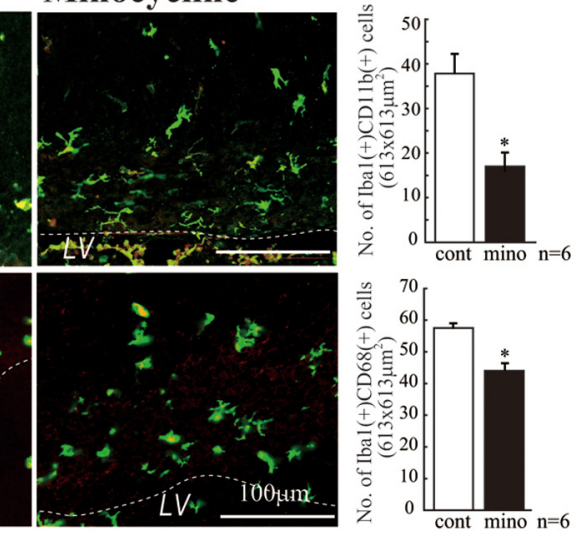

b2
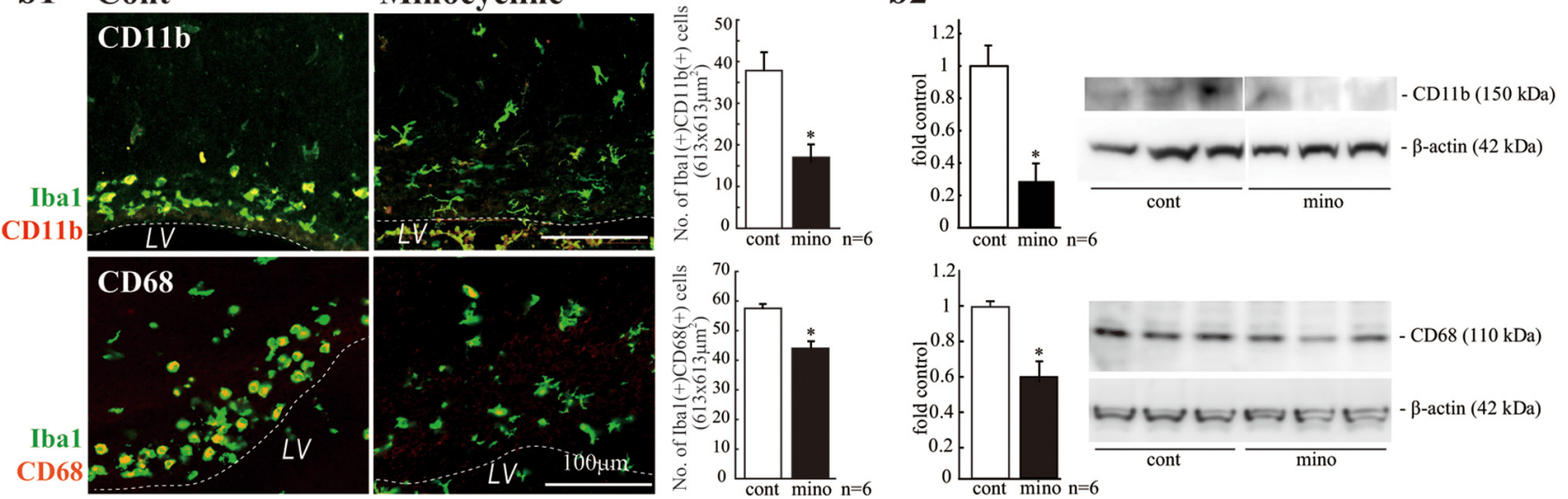

Figure 3. Minocycline suppressed microglial activation in vivo. A, Effects of minocycline on the number of Iba ${ }^{+}$cells in the SVZ and their morphologies. Minocycline was administered by intraperitoneal injection for $3 \mathrm{~d}$ beginning at P2 (30 mg/kg/d, P2-P4, $n=6 /$ group). Sagittal sections of minocycline-treated forebrains were immunostained for lba1 (green) followed by DAPI staining (cyan). Although the number of $\mathrm{lba} 1^{+}$microglia in the SVZ did not change (graph), their shape shifted from an amoeboid type to a more ramified type by minocycline (bottom). Bb1, Effects of minocycline on the expression of activation markers and the morphologies of microglia. Sagittal sections of minocycline-treated forebrains were immunostained for lba1 (green), and CD11b (red), and CD68 (red). Minocycline significantly decreased the number of cells positive for CD11b or CD68. The morphologies of the cells were also changed from amoeboid shape to more ramified shape. $\mathbf{B b 2}$, The significant decrease in the expression of CD11b and CD68 was confirmed by Western blotting of the SVZ as well. ${ }^{*} p<0.05$ (Student's $t$ test). Data are mean \pm SEM. Similar results were obtained in three independent experiments.

stained with anti-Ibal, the marker for all microglia (green: microglia), and anti-GFAP antibodies (red: neural stem cells and astrocytes) at P1, P4, P10, P14, and P30. We found that a large number of microglia accumulated in the postnatal SVZ from P1 to P10 (Fig. 1A), especially at P4. The microglia in the VZ/SVZ at $\mathrm{P} 1$ and $\mathrm{P} 4$ display an amoeboid shape, whereas those outside the SVZ have a more ramified shape (Fig. 1Aa2). At P10, the number of microglia outside the SVZ had dramatically increased; the microglia in the VZ/SVZ remained amoeboid. At P14, the number of microglia had increased further and now ramified microglia were also observed in the VZ/SVZ. At P30, the numbers of microglia in the SVZ had decreased and most of the microglia had assumed a ramified shape. Further magnified images in Figure $1 \mathrm{Aa} 3$ show that the shape of microglia in the SVZ changed gradually from amoeboid (P4) to ramified (P30). Figure $1 B$ shows the expression of CD11b (Fig. 1Bb1) and CD68 (Fig. 1Bb2) in the SVZ microglia at P10. CD11b is potentially a marker for all microglia; however, its level is highly elevated by activation. CD68 is a marker for activated microglia. The levels of CD11b and CD68 are much higher in the amoeboid microglia in the SVZ (white arrowheads) than in the ramified ones outside the SVZ (black arrowheads), indicating that the SVZ amoeboid microglia have an activated phenotype.

To examine the developmental dynamics of microglia in the SVZ temporally and spatially, we examined the distribution of microglia in coronal sections that include rostral, medial, and caudal SVZ at P1, P4, P10, and P30 (Fig. 2). Each rostrocaudal level was determined according to a previous report (Suzuki and Goldman, 2003). Coronal sections were immunostained with anti-Ibal (green: microglia) followed by DAPI staining (blue: cell nuclei) (Fig. 2B,C). The SVZ could be clearly delineated by its dense cellularity. From P1 to P10, a large number of microglia accumulated at all rostral, middle, and caudal levels. When we quantified the number of microglia in the SVZ, they gradually increased from $\mathrm{P} 1$ to $\mathrm{P} 10$, reached a maximum at $\mathrm{p} 10$, and decreased at P30 at all coronal levels (Fig. 2B,D, d1). Microglia displayed an amoeboid shape at P1, P4, and P10 but had become more ramified at P30 (Fig. 2Cc1). Among the different rostrocaudal levels, the number of microglia in the middle SVZ was significantly larger than in other levels at all ages (Fig. 2D, d2, d3). The changes in cell density (i.e., the ratio of $\mathrm{Iba}^{+} / \mathrm{DAPI}^{+}$) of microglia in the SVZ paralleled that of the number of microglia throughout the period of observation (Fig. 2E). We next examined immunostaining for CD68 in SVZ microglia. Figure 2Cc2 shows representative images of double staining with anti-Iba1 and anti-CD68. At P1 and P4, most Iba1+ microglia in the SVZ were also positive for CD68. At $\mathrm{P} 4$, the CD68 signals became much stronger. At P10, a few microglia had appeared that had little CD68. At P30, double-positive cells were markedly decreased in number. The time course of the ratio of $\mathrm{CD} 68^{+} / \mathrm{Iba} 1^{+}$ cells is shown in Figure 2F: the highest ratio was obtained at P1. The ratios at $\mathrm{P} 4$ and $\mathrm{P} 10$ were almost equivalent and then were 
A

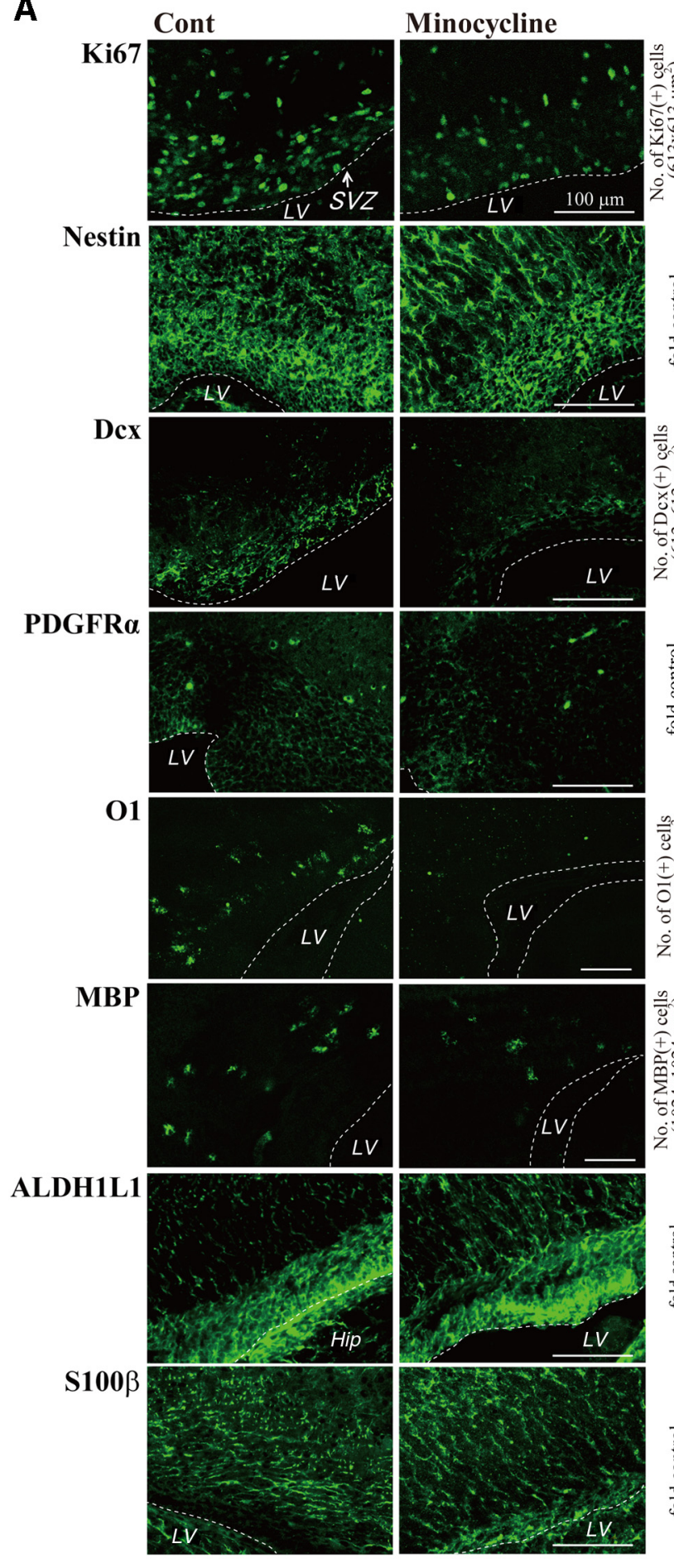

Minocycline
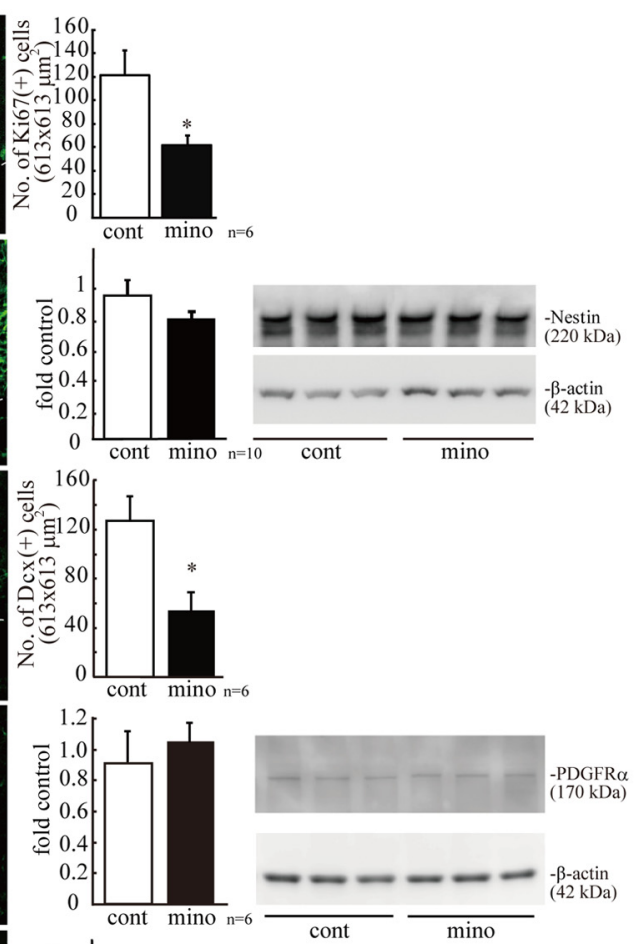

B

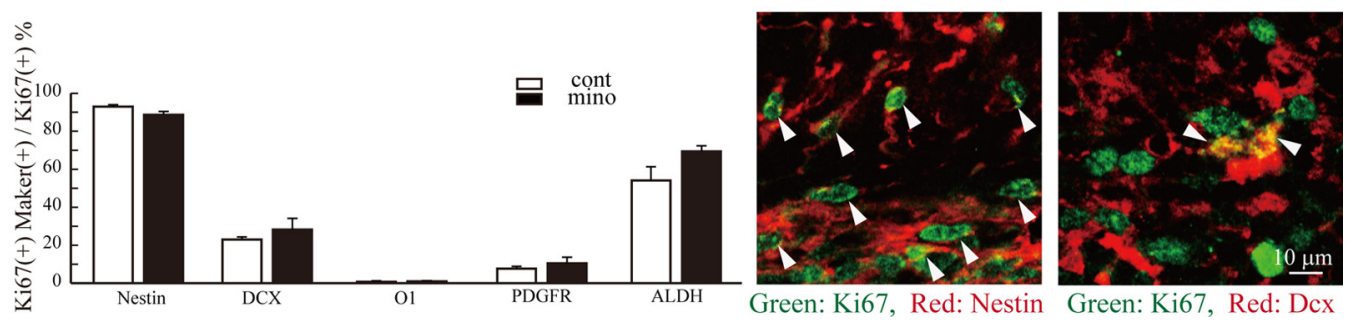

Figure 4. Minocycline decreased the numbers of proliferating cells, neuronal progenitors, and oligodendrocyte progenitors in the early postnatal SVZ. $A$, Minocycline was administered by intraperitoneal injection for $3 \mathrm{~d}$ beginning at P2 (30 mg/kg/d, P2-P4, $n=6 /$ group). Sagittal sections of forebrains were immunostained with antibodies to Ki67, nestin, Dcx, PDGFR $\alpha, 01, \mathrm{MBP}$, ALDH1L1, and S100 $\beta$. The numbers of cells positive for Ki67, Dcx, MBP, or 01 were counted, whereas the protein levels of nestin, PDGFR $\alpha$, ALDH1L1, and S100 $\beta$ (Figure legend continues.) 
A

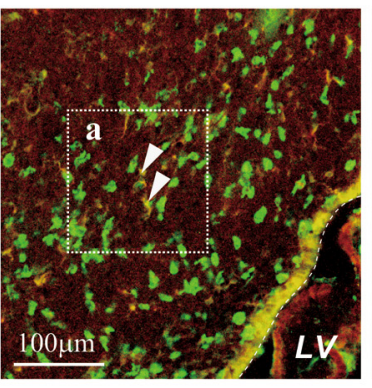

C

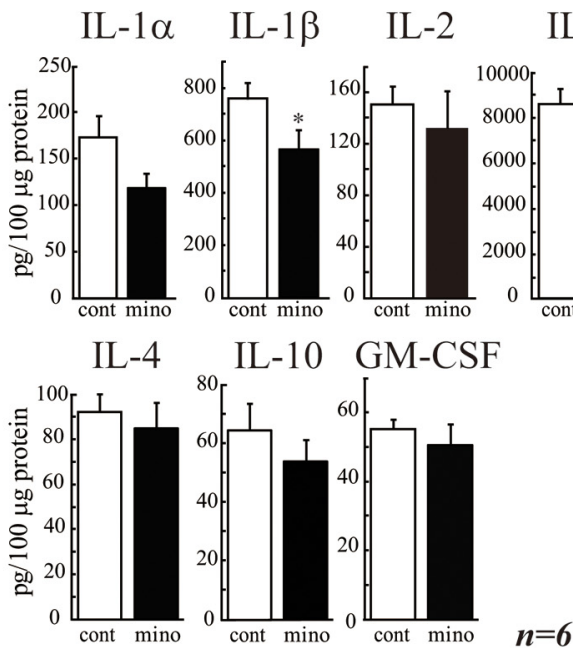

B

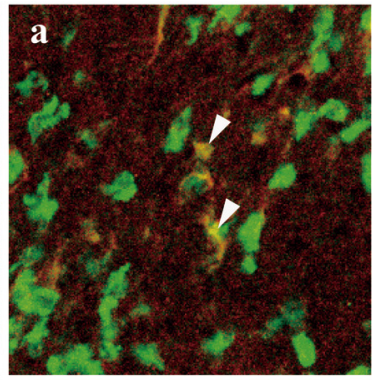

Green: CD11b

Red: IGF-1

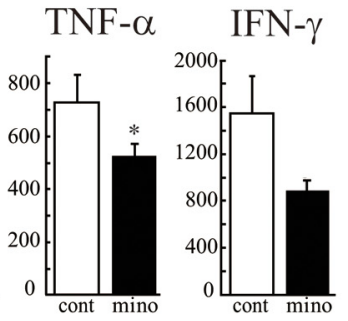

Figure 5. The activated microglia raised the cytokine levels in the SVZ. A, A subpopulation of the microglia express IGF-1 in the early postnatal SVZ, but IGF-1 is not involved in the action of activated microglia during this period. Sagittal sections were immunostained with anti-CD11b (green: microglia) and anti IGF-1 (red) antibodies. Right panel, Magnified image of the square in the left. A subpopulation of microglia is positive for IGF-1 (arrowheads). The percentage of CD11b ${ }^{+}$IGF- $1^{+}$was $43.42 \pm 6.72 \%$ in CD11b ${ }^{+}$cells. $B$, Minocycline did not affect the amount of IGF-1 in the early postnatal SVZ. Minocycline was administered by intraperitoneal injection for $3 \mathrm{~d}$ beginning at P2 ( $30 \mathrm{mg} / \mathrm{kg} / \mathrm{d}, \mathrm{P} 2-\mathrm{P4}, n=6 / \mathrm{group})$, and the amount of IGF-1 in the SVZ was quantified by ELISA. C, Minocycline decreased the amount of inflammatory cytokines in the SVZ. IL- $1 \alpha$, IL-1 $\beta$, IL-2, IL-4, IL-6, IL-10, GM-CSF, IFN- $\gamma$, and TNF- $\alpha$ levels in the SVZ tissue lysate were measured by BioPlex cytokine detection assay system. ${ }^{*} p<$ 0.05 (Student's $t$ test). $n=6$ rats/group. Data are mean \pm SEM. Similar results were obtained in two independent experiments.

remarkably decreased at P30. These results are consistent with those obtained from the sagittal sections (Fig. 1), showing the population of activated microglia that accumulated within the SVZ during the early postnatal period.

We therefore examined the specific roles of these microglia in the early postnatal SVZ. At early postnatal ages, both neurogenesis and gliogenesis are active in the SVZ (Gould et al., 1999; Wagner et al., 1999; Doetsch and Scharff, 2001; Zerlin et al., 2004; Marshall et al., 2008). To suppress the activation of microglia, we used minocycline, a tetracycline antibiotic, long used to suppress

(Figure legend continued.) were examined by Western blotting. Minocycline significantly decreased the number of Ki67 ${ }^{+}$proliferating cells and decreased the level of nestin. The number of cells positive for Dcx was significantly reduced. Minocycline decreased the numbers of cells positive for 01 and MBP, whereas the expression level of PDGFR $\alpha$ tended to increase. ${ }^{*} p<$ $0.05,{ }^{* *} p<0.01$ (Student's ttest). $n=6$ mice/group. Data are mean \pm SEM. $\boldsymbol{B}$, The ratio of the $\mathrm{Ki} 7^{+}$cells also positive for respective differentiation markers did not change in the absence or presence of minocycline (left graph). Typical images of the cells positive for Ki67 and Nestin, and the cells positive for Ki67 and Dcx in the control group are shown (right panels). We confirmed the same results in three independent experiments.

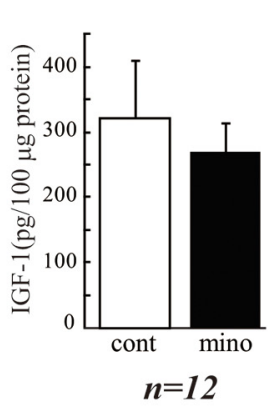

microglial activation (Tikka et al., 2001; Zhao et al., 2007). We first verified the effects of minocycline on the activation of microglia. Minocycline was administered by intraperitoneal injection for $3 \mathrm{~d}$ beginning at $\mathrm{P} 2(30 \mathrm{mg} / \mathrm{kg} / \mathrm{d}, \mathrm{P} 2-\mathrm{P} 4, n=$ 6/group), and sagittal sections of minocycline-treated rat forebrains were immunostained for Iba1, CD11b, and CD68. Minocycline did not change the numbers of Ibal-positive microglia in the VZ/SVZ (Fig. 3A, top), but it dramatically changed their shape from amoeboid to more ramified (Fig. 3A, bottom). The number of $\mathrm{CD} 11 \mathrm{~b}^{+}$cells was significantly decreased (Fig. 3Bb1, top and graph), and the decrease in CD11b levels in the SVZ was confirmed by Western blotting (Fig. $3 B b 2$, top graph and photo). The number of CD $68^{+}$cells and the level of CD68 were also decreased (Fig. 3B, bottom data). These results indicate that our administration of minocycline suppresses the activation of SVZ microglia.

We then investigated the effects of minocycline on early postnatal differentiation. After the administration of minocycline, sagittal sections were immunostained with differentiation markers: Ki67 (proliferating cells), nestin (stem cells), Dcx (neuronal progenitors), PDGFR $\alpha$ (oligodendrocyte progenitors [polydendrocytes]), O1 (oligodendrocyte progenitors [premyelinating oligodendrocytes]), MBP (mature oligodendrocyte [premyelinating and myelinating oligodendrocytes] (Nishiyama et al., 2009), ALDH1L1 (astrocyte progenitors), and $\mathrm{S} 100 \beta^{+}$(astrocytes) (Fig. 4A). The numbers of cells positive for Ki67, Dcx, O1, and MBP were counted, whereas the levels of nestin, PDGF $\alpha$, ALDH1L1, and S100 $\beta$ were examined by Western blotting because it was hard to discriminate the cell morphologies by these signals. Minocycline significantly decreased the number of $\mathrm{Ki}^{+}{ }^{+}$cells and slightly decreased the level of nestin. The number of cells positive for Dcx was also significantly reduced. Furthermore, minocycline decreased the numbers of cells positive for $\mathrm{O} 1$ and MBP, whereas the numbers of PDGFR $\alpha^{+}$cells rather tended to increase. The levels of ALDH1L1 and S100 $\beta$ did not change. These results suggest that activated microglia in the early postnatal SVZ enhance neurogenesis and oligodendrogenesis, and activated microglia affect oligodendrocyte progenitors at rather later stage of differentiation. We also performed the double staining of Ki67 with the respective differentiation markers (Fig. $4 B$ ). Although the total number of $\mathrm{Ki}^{+} 7^{+}$cells was decreased by minocycline, consistent with Figure $4 A$, the percentage of $\mathrm{Ki}^{+}{ }^{+}$cells also positive for the respective differentiation markers did not change in the absence or presence of minocycline (Fig. 4B, left graph), suggesting that minocycline did not affect the proliferation of progenitors of the specific cell types. Typical images of the SVZ cells positive for 
Ki67 and Nestin, and the cells positive for Ki67 and Dcx in the control group are shown (Fig. $4 B$, right panels).

Butovsky et al. (2006a) have reported that IGF-1 released from activated microglia promoted neurogenesis and oligodendrogenesis from adult stem/progenitor cells. We examined whether microglia in the early postnatal SVZ produce IGF-1 (Fig. 5A). Microglia did contain IGF-1 protein, but the percentage of CD11b ${ }^{+}$ cells also positive for IGF- ${ }^{+}{ }^{+}$was $43.42 \pm$ $6.72 \%$. Furthermore, the amount of IGF-1 in the SVZ tissue lysates was not decreased by minocycline (Fig. $5 B$ ). These results suggest that, although a fraction of activated microglia in the early postnatal SVZ did produce IGF-1, the effects of activated microglia on neurogenesis and oligodendrogenesis obtained in our study were independent of IGF-1. Activated microglia release a number of cytokines. In some cases other than pathological conditions, cytokines also have physiological roles (Schäfers and Sorkin, 2008; Spedding and Gressens, 2008; CamachoArroyo et al., 2009; Miller et al., 2009; Spooren et al., 2011). We therefore investigated whether the SVZ microglia cause the increase in cytokine concentrations in the early postnatal SVZ (Fig. 5C). We examined the effects of minocycline on the levels of IL- $1 \alpha$, IL- $1 \beta$, IL- 2 , IL- 4 , IL-6, IL10 , GM-CSF, IFN- $\gamma$, and TNF- $\alpha$. To measure multiple cytokines in a small volume of tissue samples simultaneously, we used the BioPlex cytokine detection assay system (Bio-Rad). The levels of IL-1 $\beta$, IL-6, and TNF- $\alpha$ were significantly decreased by the 3-day intraperitoneal administration of minocycline (Fig. 5C). Although the difference was not significant, the level of IFN- $\gamma$ also tended to be decreased.

To examine more directly whether these cytokines affected neurogenesis and oligodendrogenesis, we performed in vitro experiments, coculturing neural stem cells with activated microglia. Microglia cultured independently of neurospheres on transwells were activated by LPS (10 ng/ $\mathrm{ml}, 30 \mathrm{~min})$ in the presence or absence of minocycline $(10 \mu \mathrm{M})$. The microglia were carefully washed to remove residual LPS and minocycline, and then the transwell on which microglia were cultured was set onto the neurosphere cultures in prodifferentiation conditions. The activated microglia significantly increased the number of $\beta 3$-tubulin ${ }^{+}$and $\mathrm{O}_{4}{ }^{+}$cells but had no effects on $\mathrm{GFAP}^{+}$cells in neurospheres (Fig. 6A,B). Minocycline almost completely suppressed the effects of activated microglia on the numbers of cells positive
A
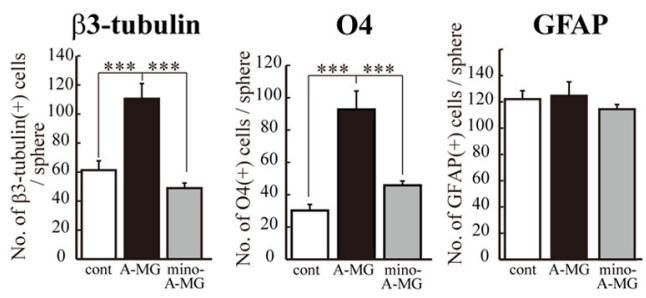

B

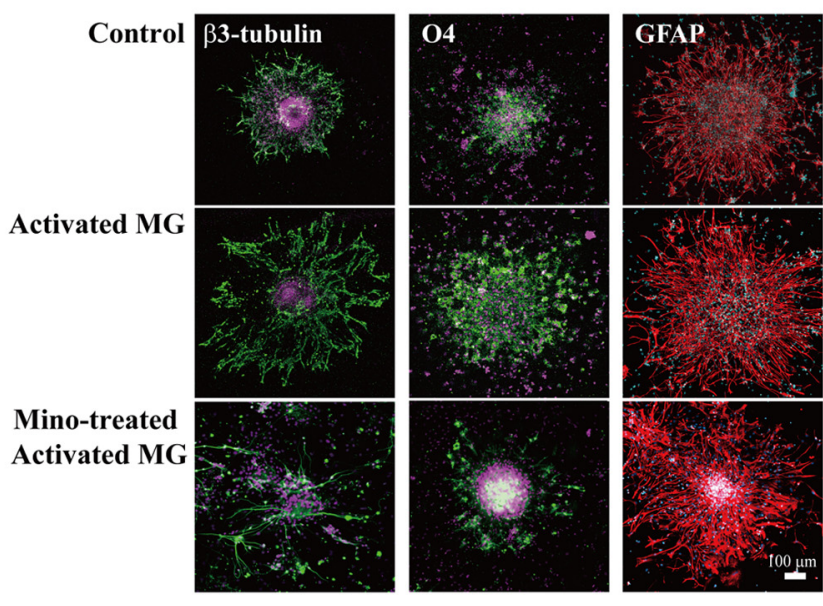

C

$\beta 3$-tubulin

$\operatorname{PDGFR} \alpha$

04

GFAP
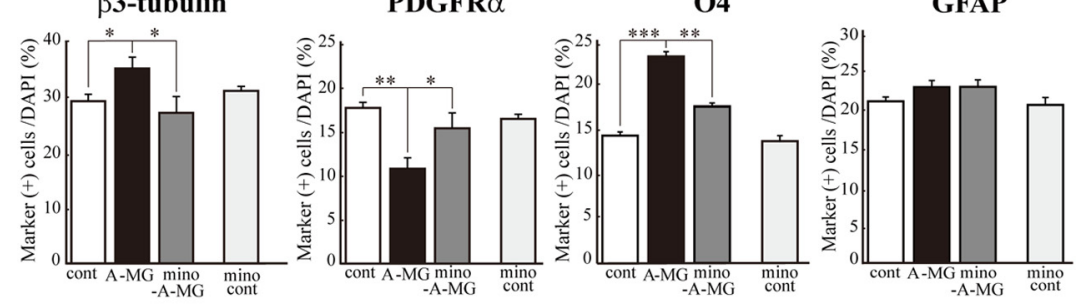

D

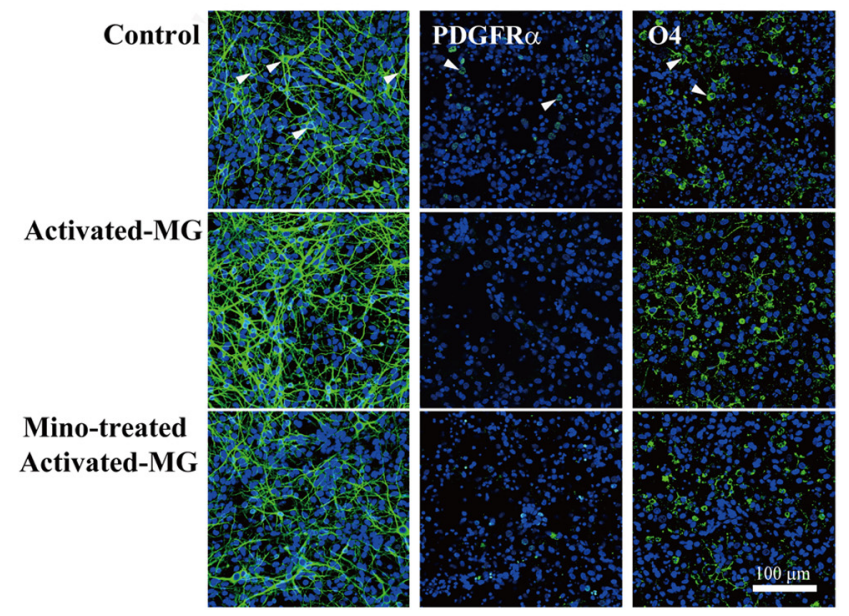

Figure 6. The reproduction of the enhancement of neurogenesis and oligodendrogenesis by activated microglia in vitro. Microglia cultured independently of neurosphere on transwells were activated by LPS $(10 \mathrm{ng} / \mathrm{ml}, 30 \mathrm{~min})$ in the presence or absence of minocycline $(10 \mu \mathrm{M})$, washed carefully, and the transwells were set onto the neurospheres or dissociated cells from neurosphere in prodifferentiation conditions. After differentiation periods suitable for neurons ( $7 \mathrm{~d}$ ) or oligodendrocytes (11 d), neurospheres were stained for $\beta 3$-tubulin (green), PDGFR $\alpha$ (green), 04 (green), GFAP (red), and TOT03 (cyan). To check the effects of minocycline alone, dissociated cells were incubated in the presence of minocycline $(10 \mu \mathrm{m})$ for $7 \mathrm{~d}$. $A$, Quantification of the numbers of neurons, oligodendrocyte progenitors, or astrocytes differentiated from neurospheres cocultured with activated microglia in the presence or absence of minocycline. ${ }^{* * *} p<0.001$ (Tukey's test by ANOVA). $n=12$ neurospheres/group. Data are mean \pm SEM. $\boldsymbol{B}$, Representative immunostained images of neurospheres cocultured with activated microglia in the presence or absence of minocycline. C, The effects of activated microglia on differentiation of single cells dissociated from neurospheres in the presence or absence of minocycline. The effects of minocycline alone were also shown (mino-cont in each graph). ${ }^{*} p<0.05,{ }^{* *} p<0.01$, ${ }^{* * *} p<0.001$. (Tukey's test by ANOVA). $n=12$ neurospheres/group. Data are mean \pm SEM. $\boldsymbol{D}$, Images of cells immunostained for differentiation markers. Arrowheads indicate the representative cells positive for the differentiation markers. 
A

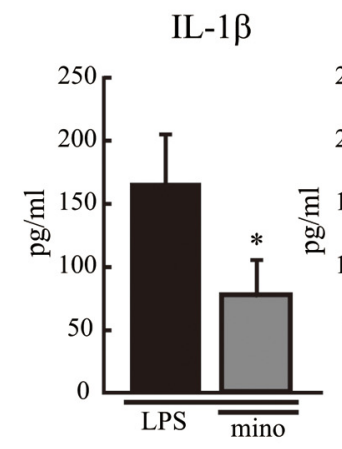

B

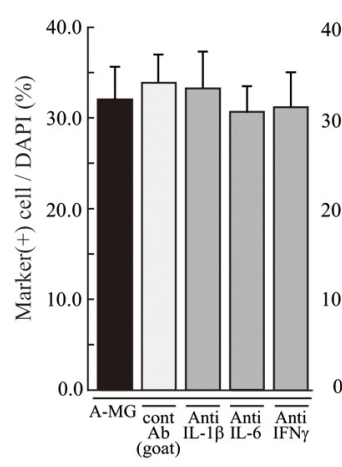

C

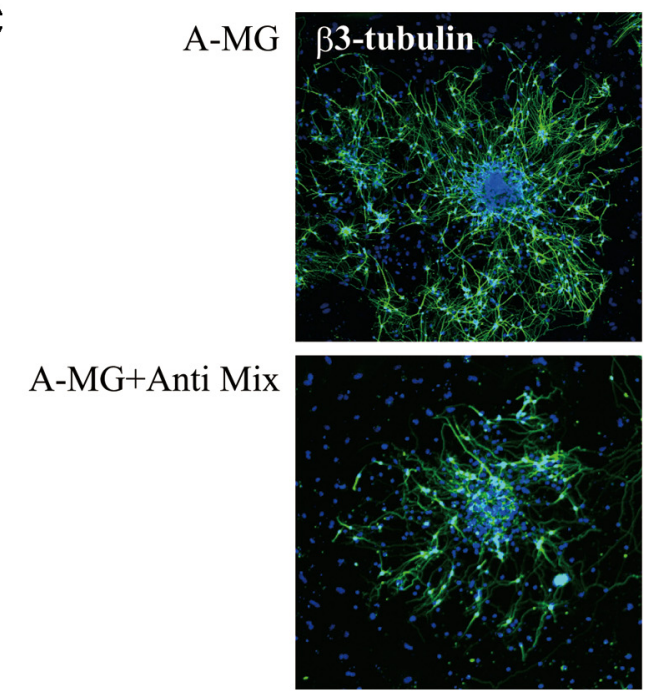

IL-6

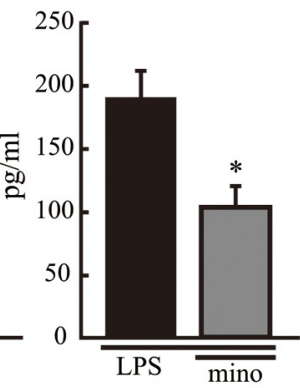

$\beta 3$-tubulin
TNF- $\alpha$

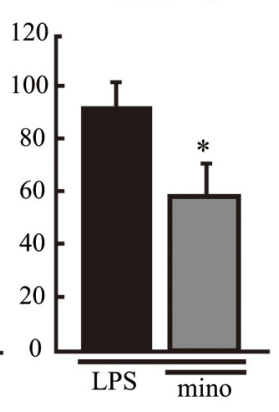

IFN- $\gamma$

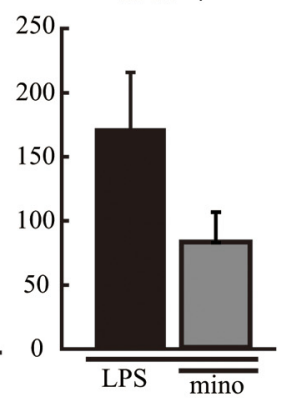

O4
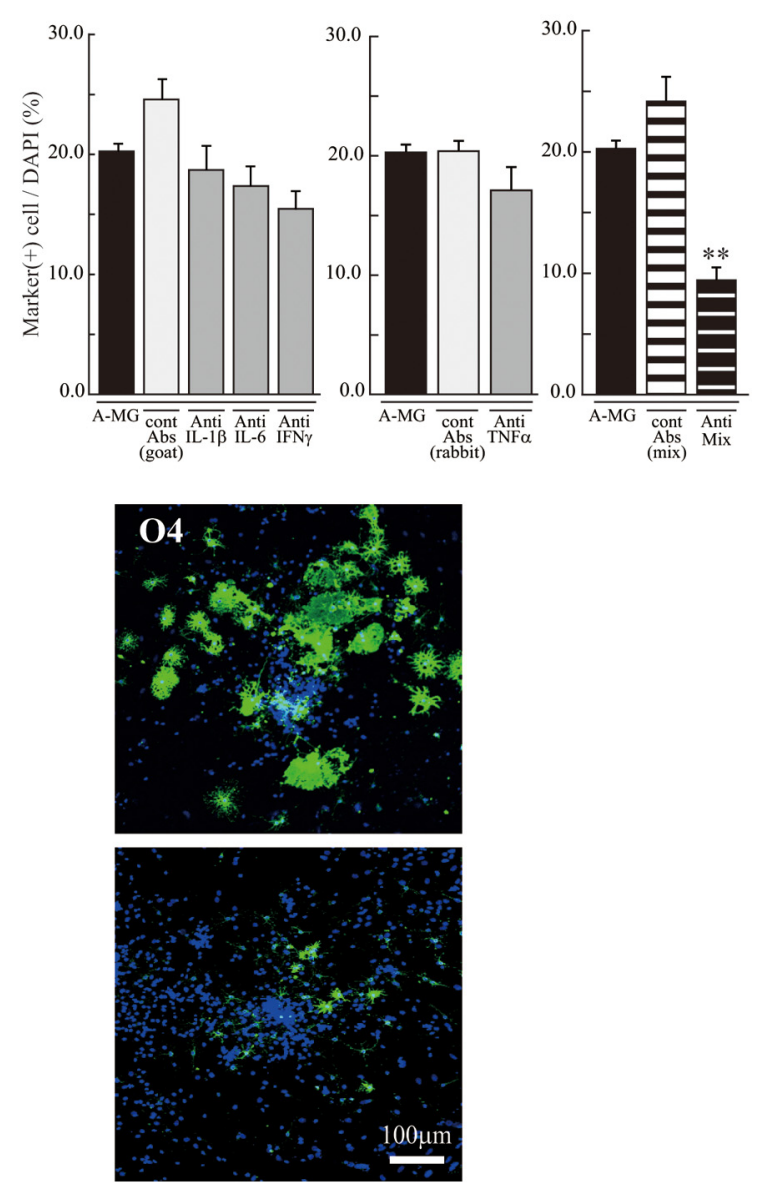

Figure 7. The in vitro enhancement of neurogenesis and oligodendrogenesis by activated microglia was suppressed by the mixture of function-blocking antibodies (anti-IL-1 $\beta$, anti-IL- 6 , anti-TNF- $\alpha$, and anti-IFN- $\gamma$ ). $\boldsymbol{A}$, The release of IL-1 $\beta$, IL-6, TNF- $\alpha$, or IFN- $\gamma$ from activated microglia was suppressed by minocycline. Cultured microglia were activated by LPS (10 ng/ml, $30 \mathrm{~min}$ ) in the absence and presence of minocycline $(10 \mu \mathrm{m})$. The concentration of each cytokine in the supernatant was measured by ELISA $24 \mathrm{~h}$ after. ${ }^{*} p<0.05$ (Student's $t$ test). Data are mean \pm SEM. $B$, Effects of function-blocking antibodies to IL-1 $\beta$, IL-6, TNF- $\alpha$, and IFN- $\gamma$ on enhanced neurogenesis and oligodendrogenesis by the activated microglia. The neurospheres were differentiated in the absence or presence of functional blocking antibodies (goat anti-rat IL-1 $\beta$ antibody, goat anti-rat IL-6 antibody, TNF- $\alpha$ antibody, or goat anti-mouse/rat IFN- $\gamma$ antibody) (1 $\mu \mathrm{g} / \mathrm{ml} \mathrm{for} \mathrm{each)} \mathrm{and}$ a mixture of all of these antibodies. After a differentiation period suitable for neurons ( $7 \mathrm{~d}$ ) or oligodendrocytes ( $11 \mathrm{~d}$ ), neurospheres were stained for $\beta 3$-tubulin (green), 04 (green), and T0T03 (cyan). The data of single function blocking antibodies were compared with the controls, which include the same concentration of isotype-matched control lgGs (1 $\mu \mathrm{g} / \mathrm{ml}$ for each). The data of the mixture of function blocking antibodies were compared with the controls, which include the same concentrations of isotype-matched control lgGs (i.e., $3 \mu \mathrm{g} / \mathrm{ml}$ of normal goat lgG control and 1 $\mu \mathrm{g} / \mathrm{ml}$ of rabbit lgG control). ${ }^{*} p<0.05 .{ }^{* *} p<0.01$, versus isotype-matched control lgG group (Tukey's test by ANOVA). Data are mean \pm SEM. C, Representative immunostained images of neurospheres cocultured with activated microglia in the absence or presence of the mixture of the function-blocking antibodies. We confirmed the same results in three independent experiments.

for $\beta 3$-tubulin or $\mathrm{O} 4$. We further confirmed these results using a differentiation assay with cells dissociated from neurospheres (Fig. 6C,D). With this protocol, the morphology of each cell could be discriminated more clearly. Consistent with the results described above, an increase in the numbers of cells positive for $\beta 3$-tubulin and $\mathrm{O} 4$ was induced by activated microglia (Fig. $6 C, D)$. Of note, PDGFR $\alpha^{+}$cells were decreased by activated mi- croglia, whereas $\mathrm{O} 4{ }^{+}$cells were increased by activated microglia. Minocycline suppressed both of these effects, suggesting that activated microglia affect the later stage of oligodendrogenesis, thereby reducing the size of $\mathrm{PDGF} \alpha^{+}$progenitor pool. In this experiment, we also checked the effects of minocycline alone (10 $\mu \mathrm{M}$ ) on neurogenesis and oligodendrogenesis (Fig. 6C, "minocont" in each graph). Minocycline did not affect the numbers of 
A

\section{$\beta 3-$ tubulin}

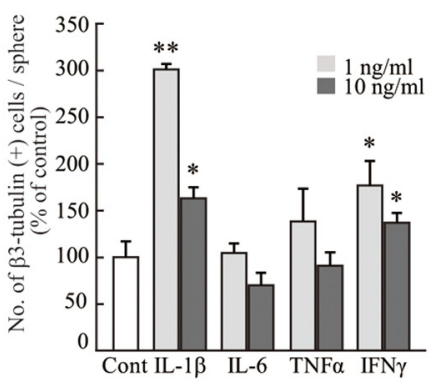

O4

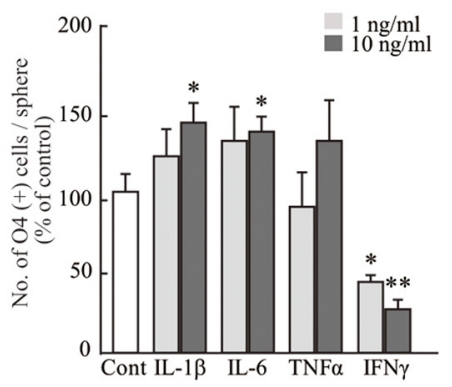

B

\section{$\beta 3-$ tubulin}
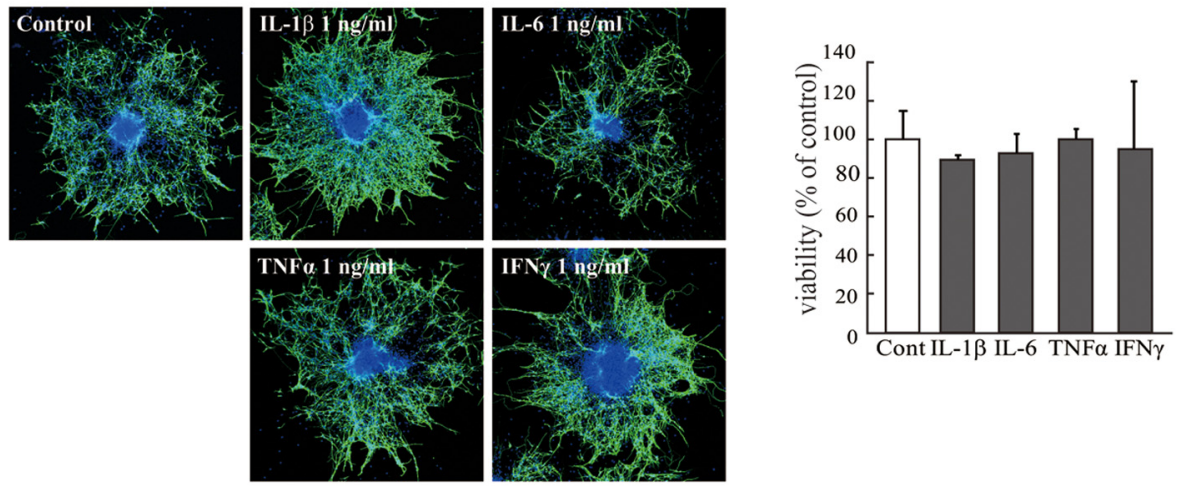
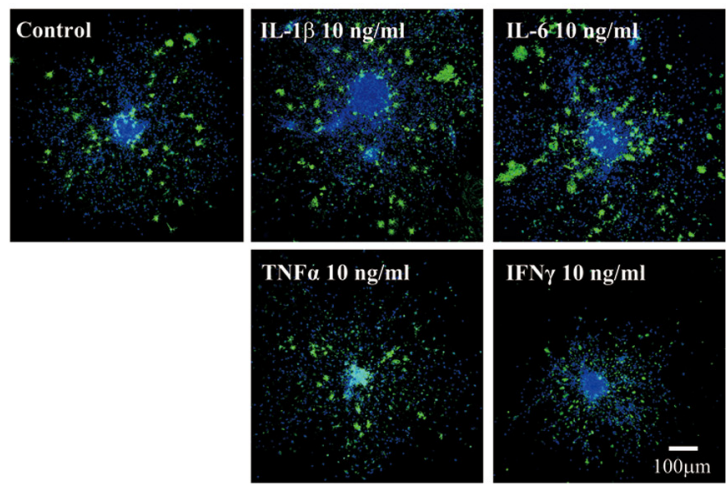

Figure 8. The effect of each cytokine on neurogenesis and oligodendrogenesis. Neurospheres were incubated for differentiation period suitable for neurons (7 $\mathrm{d}$ ) or oligodendrocytes ( $11 \mathrm{~d}$ ) in the presence of each single cytokine (rlL-1 $\beta$, rlL-6, rTNF- $\alpha$, or rlFN- $\gamma$ ) at 1-10 ng/ml. Neurospheres were stained for $\beta 3$-tubulin (green), 04 (green), followed by T0T03 (cyan). $\boldsymbol{A}, 0$ Quantification of the effects of cytokines on neurogenesis and oligodendrogenesis. IL- $1 \beta$ and IFN- $\gamma$ significantly enhanced neurogenesis at $1 \mathrm{ng} / \mathrm{ml}$. IL- $1 \beta$ and IL-6 enhanced oligodendrogenesis at $10 \mathrm{ng} / \mathrm{ml}$. ${ }^{*} p<0.05$ versus control (Tukey's test by ANOVA). ${ }^{* *} p<0.01$ versus control (Tukey's test by ANOVA). $n=8$ neurospheres/group. Data are mean \pm SEM. $\boldsymbol{B}$, Representative images of neurospheres immunostained for $\beta 3$-tubulin and 04 after differentiation in the presence of the cytokine. $\boldsymbol{C}$, The effect of each cytokine ( $10 \mathrm{ng} / \mathrm{ml})$ on cell viability. They did not affect cell viability at $10 \mathrm{ng} / \mathrm{ml}$. The same results were obtained in two independent experiments.

cells positive for $\beta 3$-tubulin, O4, PDGFR $\alpha$, or GFAP, indicating that minocycline itself had little direct effects on neurogenesis and oligodendrogenesis. Together, these results demonstrated that we could reproduce the in vivo data in an in vitro coculture experiment. We further confirmed that activated microglia enhanced neurogenesis and oligodendrogenesis, and minocycline specifically suppressed the effects of microglia. We therefore examined the effects of minocycline on the release of IL- $1 \beta$, IL- 6 , TNF- $\alpha$, and IFN- $\gamma$ from activated microglia in vitro. In the presence of minocycline, the release of all of these cytokines was significantly suppressed (Fig. $7 A$ ), consistent with in vivo data (Fig. $5 C$ ). To examine the extent of the contribution of each cytokine to the enhancement of neurogenesis and oligodendrogenesis, we applied function-blocking antibodies to IL- $1 \beta$, IL- 6 , TNF- $\alpha$, and IFN- $\gamma(1 \mu \mathrm{g} / \mathrm{ml})$ to cocultures of activated microglia and neurospheres (Fig. $7 B$ ). The same concentration of isotype-matched control IgG (both of goat and rabbit) $(1 \mu \mathrm{g} / \mathrm{ml})$ did not have any effects on either neurogenesis or oligodendrogenesis. Unexpectedly, any single function-blocking antibody to IL- $1 \beta$, IL-6, TNF- $\alpha$, or IFN- $\gamma$ did not change the effects of activated microglia on neurogenesis and oligodendrogenesis (Fig. $7 B$ ). We then tried a mixture of all of these function-blocking antibodies (goat antirat IL- $1 \beta$ antibody, goat anti-rat IL- 6 antibody, TNF- $\alpha$ antibody, and goat anti-mouse/rat IFN- $\gamma$ antibody, $1 \mu \mathrm{g} / \mathrm{ml}$ for each).
When compared with the control which included the same concentrations of isotype-matched control IgGs (i.e., $3 \mu \mathrm{g} / \mathrm{ml}$ of normal goat IgG control and $1 \mu \mathrm{g} / \mathrm{ml}$ of rabbit IgG control), the effects of activated microglia were significantly suppressed by a mixture of all of these function-blocking antibodies (Fig. 7B, Anti Mix in the right graphs in $\beta 3$-tubulin and $\mathrm{O} 4$, respectively). The representative images of the expression of $\beta 3$-tubulin (left) or $\mathrm{O} 4$ (right) in neurospheres cocultured with activated microglia in the presence of the mixture of function-blocking antibodies are shown in Figure 7C. We also examined the direct effects of each single cytokine on neurogenesis and oligodendrogenesis separately (Fig. 8). IL-1 $\beta$ and IFN- $\gamma$ enhanced neurogenesis at $1 \mathrm{ng} /$ $\mathrm{ml}$, although the effects became weaker at $10 \mathrm{ng} / \mathrm{ml}$ (Fig. $8 A$ ). IL- $1 \beta$ and IL- 6 enhanced oligodendrogenesis at $10 \mathrm{ng} / \mathrm{ml}$ (Fig. $8 A)$. IFN- $\gamma$ suppressed oligodendrogenesis. These results suggest that IL- $1 \beta$ and IFN- $\gamma$ are important for neurogenesis, whereas IL- $1 \beta$ and IL- 6 are important for oligodendrogenesis, and the combinations and concentrations optimal for neurogenesis and oligodendrogenesis are different. Representative data of the neurospheres treated with the cytokines are shown in Figure $8 B$. We confirmed that each single cytokine did not affect cell viability at $10 \mathrm{ng} / \mathrm{ml}$ in our experimental protocol (Fig. 8C). These in vitro data indicate that activated microglia regulate neurogenesis and oligodendrogenesis through released cytokines, and the cyto- 
kines produce their effects in a synergistic manner. It also appears that the combinations and concentrations optimal for neurogenesis and oligodendrogenesis are different.

\section{Discussion}

In the postnatal mammalian brain, neural stem cells (NSCs) are mainly localized in two areas: the forebrain SVZ (Doetsch and Scharff, 2001) and the subgranular zone of the dentate gyrus (Zerlin et al., 2004) of the hippocampus (Gould et al., 1999; Lie et al., 2004). The microenvironments that are permissive for neurogenesis and gliogenesis are composed of a variety of cell types, such as stem cells, progenitor cells, astrocyte cells, and microglial cells. Increasing evidence indicates the importance of the surrounding glial cells in neurogenesis (Doetsch et al., 1999; Temple, 2001). Goings et al. (2006) have shown that microglia in the adult SVZ are semiactivated, but microglial contribution to neurogenesis is complex. So far, the role of microglia in neurogenesis has been examined mainly in pathological conditions (Ekdahl et al., 2003; Monje et al., 2003). Activated microglia in inflammatory settings, such as intraperitoneal administration of LPS, inhibited neurogenesis (Ekdahl et al., 2003; Monje et al., 2003; Cacci et al., 2008). However, a growing number of studies have suggested that activated microglia are beneficial for neurogenesis (Aarum et al., 2003; Butovsky et al., 2005, 2006a; Walton et al., 2006; Ziv et al., 2006; Hanisch and Kettenmann, 2007; Ekdahl et al., 2009; Bachstetter et al., 2011; Ekdahl, 2012; Vukovic et al., 2012), even in pathological conditions, such as an animal model of multiple sclerosis (Butovsky et al., 2006b), ischemia (Thored et al., 2009; Deierborg et al., 2010), and epilepsy (Bonde et al., 2006). Such variability concerning the effects of microglia on neurogenesis may reflect the different polarization of microglia and/or the precise status of NSCs/neuronal progenitor cells (NPCs) (Cacci et al., 2008; Li et al., 2010; Ekdahl, 2012; Ortega et al., 2013), and crosstalk between them (Mosher et al., 2012).

Concerning the origin of microglia, various data have been reported. In vivo lineage tracing studies have established that microglia differentiate from primitive myeloid progenitors that arise before embryonic day 8 and are identified in the CNS parenchyma even before definitive hematopoiesis (Ginhoux et al., 2010), although it has been shown that microglia migrate from lateral ventricle into brain via SVZ in the postnatal brain (Mohri et al., 2003). Microglia in the embryonic SVZ limit the production of cortical neurons by phagocytosing neural precursor cells (Cunningham et al., 2013). Even in the adult brain, microglia appear densely populated in neurogenic niches, such as the SVZ (Mosher et al., 2012), and appear more activated in the adult SVZ than in non-neurogenic zones (Goings et al., 2006). Although these data strongly suggest that microglia play important roles in CNS development and an increasing number of studies have elucidated various roles of microglia during developmental periods (Wu et al., 1993; Pont-Lezica et al., 2011; Tremblay et al., 2011), the detailed dynamics of microglia in the SVZ from early postnatal stages to a young adult stage remain to be elucidated. Furthermore, few studies have examined the role of microglia in normal developmental processes during this period. In this study, we found that activated microglia first accumulated in the SVZ and then dispersed to white matter, where they became more ramified. In addition, the number of activated microglia was largest in the medial SVZ throughout the studied period (P30). We here elucidated that activated microglia in the early postnatal SVZ enhance neurogenesis and oligodendrogenesis through the mechanisms described below. Our present data and the previous reports concerning developmental changes in the distribution suggest that the developmental roles of microglia in the SVZ are not transient but more general throughout life.

Using a combination of in vivo and in vitro approaches, we demonstrated that these activated microglia in the early postnatal SVZ enhanced neurogenesis and oligodendrogenesis through releasing cytokines. Butovsky et al. (2006a) reported that the beneficial effects of microglia on adult neurogenesis/oligodendrogenesis was achieved by IGF- 1 after IL- 4 and IFN- $\gamma$ release from activated microglia. In our study, although the activated microglia in the early postnatal SVZ did produce IGF-1, the effects of activated microglia on neurogenesis and oligodendrogenesis observed here were independent of IGF-1. We clarified that the SVZ microglia facilitate neurogenesis and oligodendrogenesis via production of cytokines. Interestingly, in in vitro coculture experiments, the enhancement of neurogenesis and oligodendrogenesis was suppressed by a mixture of function-blocking antibodies (anti-IL- $1 \beta$, anti-IL-6, anti-TNF- $\alpha$, anti-IFN- $\gamma$ ), but not by a single function-blocking antibody. These results suggest that microglial cytokines enhance neurogenesis and oligodendrogenesis in combinations. In support of this, among the cytokines we examined, only IL-1 $\beta$ and IFN- $\gamma$ enhanced neurogenesis, whereas only IL- $1 \beta$ and IL- 6 showed potentials of enhancing oligodendrogenesis. Previous reports have shown that NPCs express IL- $1 \beta$, IL-1RI and IL-1RII, and IL- $1 \beta$ regulates the proliferation and differentiation of NPCs (Wang et al., 2007). It has been shown that IL- $1 \beta$ promotes proliferation and differentiation of oligodendrocyte progenitor cells (Vela et al., 2002). Furthermore, IL-6 and IL-6R are reported to promote neurogenesis and gliogenesis (Islam et al., 2009; Oh et al., 2010). Li et al. (2010) showed that IFN- $\gamma$ stimulated neurosphere formation from embryonic brain, but the effects of IFN- $\gamma$ are modified in the presence of microglia, supporting the complementary interactions between cytokines.

These proinflammatory cytokines had been thought to cause suppression of neurogenesis in pathological conditions, such as chronic LPS stimulation (Monje et al., 2003), allergic encephalomyelitis (Ben-Hur et al., 2003), and status epilepticus (Iosif et al., 2006; Koo and Duman, 2008). However, recent reports have shown that that the different polarizations of microglia are induced by different application protocols of LPS (Cacci et al., 2008), suggesting that the combination and the concentration of cytokines released by microglia change depending on the ambient conditions. Indeed, some previous reports suggest that each cytokine reveals different effects at different concentrations (Bernardino et al., 2008; Cacci et al., 2008; Das and Basu, 2008; Russo et al., 2011). Bernardino et al. (2008) have shown that TNF- $\alpha$ results in proliferation of neural stem cells at $1 \mathrm{ng} / \mathrm{ml}$ but caused apoptosis at $10-100 \mathrm{ng} / \mathrm{ml}$. Microglia in the developmental brains may sense the change of environment and release a certain combination of cytokines at suitable concentrations for neurogenesis and oligodendrogenesis, whereas overactivation of microglia in pathological inflammation or nerve injury induces massive proinflammatory cytokine production, resulting in the suppression of neurogenesis. Nakanishi et al. (2007) showed that IL-6 promoted astrocytogenesis from the SVZ neurospheres. In our study, however, although activated microglia release IL-6, the effects on astrocytogenesis were not observed either in vivo or in vitro. This might be because of different medium compositions (i.e., growth factors) used for differentiation of neurosphere. Compared with the other cytokines, only IFN- $\gamma$ suppressed oligodendrogenesis, suggesting that a proper concentration range of IFN- $\gamma$ to enhance oligodendrogenesis might be narrower than the other cytokines. 
Of interest, our results suggest that activated microglia significantly increased $\mathrm{O}^{+}$cells while decreasing PDGFR $\alpha^{+}$cells. These results suggest that activated microglia enhance oligodendrogenesis at later stages of oligodendrocyte differentiation. Recently, Miron et al. (2013) showed that a switch from M1 to M2 occurred in microglia during remyelination, and oligodendrocyte differentiation was enhanced by M2 cell releasing factors. A comprehensive analysis about the released factors from microglia, including cytokines, and the precise identification of the cell population (NSCs and/or NPCs) that are responsive to these factors will be necessary to understand fully the mechanisms underlying the effects of microglia on neurogenesis and gliogenesis.

In conclusion, we have found a population of activated microglia accumulating in the early postnatal SVZ that facilitate neurogenesis and oligodendrogenesis. A synergism among cytokines was important for the effects. To our knowledge, this is the first report to show that microglia regulate cell differentiation via releasing cytokines in early postnatal brain development.

\section{References}

Aarum J, Sandberg K, Haeberlein SL, Persson MA (2003) Migration and differentiation of neural precursor cells can be directed by microglia. Proc Natl Acad Sci U S A 100:15983-15988. CrossRef Medline

Bachstetter AD, Morganti JM, Jernberg J, Schlunk A, Mitchell SH, Brewster KW, Hudson CE, Cole MJ, Harrison JK, Bickford PC, Gemma C (2011) Fractalkine and CX 3 CR1 regulate hippocampal neurogenesis in adult and aged rats. Neurobiol Aging 32:2030-2044. CrossRef Medline

Ben-Hur T, Ben-Menachem O, Furer V, Einstein O, Mizrachi-Kol R, Grigoriadis N (2003) Effects of proinflammatory cytokines on the growth, fate, and motility of multipotential neural precursor cells. Mol Cell Neurosci 24:623-631. CrossRef Medline

Bernardino L, Agasse F, Silva B, Ferreira R, Grade S, Malva JO (2008) Tumor necrosis factor-alpha modulates survival, proliferation, and neuronal differentiation in neonatal subventricular zone cell cultures. Stem Cells 26:2361-2371. CrossRef Medline

Bonde S, Ekdahl CT, Lindvall O (2006) Long-term neuronal replacement in adult rat hippocampus after status epilepticus despite chronic inflammation. Eur J Neurosci 23:965-974. CrossRef Medline

Butovsky O, Talpalar AE, Ben-Yaakov K, Schwartz M (2005) Activation of microglia by aggregated beta-amyloid or lipopolysaccharide impairs MHC-II expression and renders them cytotoxic whereas IFN-gamma and IL-4 render them protective. Mol Cell Neurosci 29:381-393. CrossRef Medline

Butovsky O, Ziv Y, Schwartz A, Landa G, Talpalar AE, Pluchino S, Martino G, Schwartz M (2006a) Microglia activated by IL-4 or IFN-gamma differentially induce neurogenesis and oligodendrogenesis from adult stem/ progenitor cells. Mol Cell Neurosci 31:149-160. CrossRef Medline

Butovsky O, Landa G, Kunis G, Ziv Y, Avidan H, Greenberg N, Schwartz A, Smirnov I, Pollack A, Jung S, Schwartz M (2006b) Induction and blockage of oligodendrogenesis by differently activated microglia in an animal model of multiple sclerosis. J Clin Invest 116:905-915. CrossRef Medline

Cacci E, Ajmone-Cat MA, Anelli T, Biagioni S, Minghetti L (2008) In vitro neuronal and glial differentiation from embryonic or adult neural precursor cells are differently affected by chronic or acute activation of microglia. Glia 56:412-425. CrossRef Medline

Camacho-Arroyo I, López-Griego L, Morales-Montor J (2009) The role of cytokines in the regulation of neurotransmission. Neuroimmunomodulation 16:1-12. CrossRef Medline

Cunningham CL, Martínez-Cerdeño V, Noctor SC (2013) Microglia regulate the number of neural precursor cells in the developing cerebral cortex. J Neurosci 33:4216-4233. CrossRef Medline

Das S, Basu A (2008) Inflammation: a new candidate in modulating adult neurogenesis. J Neurosci Res 86:1199-1208. CrossRef Medline

Deierborg T, Roybon L, Inacio AR, Pesic J, Brundin P (2010) Brain injury activates microglia that induce neural stem cell proliferation ex vivo and promote differentiation of neurosphere-derived cells into neurons and oligodendrocytes. Neuroscience 171:1386-1396. CrossRef Medline

Doetsch F, Scharff C (2001) Challenges for brain repair: insights from adult neurogenesis in birds and mammals. Brain Behav Evol 58:306-322. CrossRef Medline
Doetsch F, García-Verdugo JM, Alvarez-Buylla A (1999) Regeneration of a germinal layer in the adult mammalian brain. Proc Natl Acad Sci U S A 96:11619-11624. CrossRef Medline

Ekdahl CT (2012) Microglial activation- tuning and pruning adult neurogenesis. Front Pharmacol 3:41. CrossRef Medline

Ekdahl CT, Claasen JH, Bonde S, Kokaia Z, Lindvall O (2003) Inflammation is detrimental for neurogenesis in adult brain. Proc Natl Acad Sci U S A 100:13632-13637. CrossRef Medline

Ekdahl CT, Kokaia Z, Lindvall O (2009) Brain inflammation and adult neurogenesis: the dual role of microglia. Neuroscience 158:1021-1029. CrossRef Medline

Ginhoux F, Greter M, Leboeuf M, Nandi S, See P, Gokhan S, Mehler MF, Conway SJ, Ng LG, Stanley ER, Samokhvalov IM, Merad M (2010) Fate mapping analysis reveals that adult microglia derive from primitive macrophages. Science 330:841-845. CrossRef Medline

Goings GE, Kozlowski DA, Szele FG (2006) Differential activation of microglia in neurogenic versus non-neurogenic regions of the forebrain. Glia 54:329-342. CrossRef Medline

Gould E, Reeves AJ, Graziano MS, Gross CG (1999) Neurogenesis in the neocortex of adult primates. Science 286:548-552. CrossRef Medline

Hamanoue M, Matsuzaki Y, Sato K, Okano HJ, Shibata S, Sato I, Suzuki S, Ogawara M, Takamatsu K, Okano H (2009) Cell surface N-glycans mediated isolation of mouse neural stem cells. J Neurochem 110:1575-1584. CrossRef Medline

Hanisch UK, Kettenmann H (2007) Microglia: active sensor and versatile effector cells in the normal and pathologic brain. Nat Neurosci 10:13871394. CrossRef Medline

Hirasawa T, Ohsawa K, Imai Y, Ondo Y, Akazawa C, Uchino S, Kohsaka S (2005) Visualization of microglia in living tissues using Iba1-EGFP transgenic mice. J Neurosci Res 81:357-362. CrossRef Medline

Ignácio AR, Müller YM, Carvalho MS, Nazari EM (2005) Distribution of microglial cells in the cerebral hemispheres of embryonic and neonatal chicks. Braz J Med Biol Res 38:1615-1621. Medline

Inoue K (2008) Purinergic systems in microglia. Cell Mol Life Sci 65:30743080. CrossRef Medline

Iosif RE, Ekdahl CT, Ahlenius H, Pronk CJ, Bonde S, Kokaia Z, Jacobsen SE, Lindvall O (2006) Tumor necrosis factor receptor 1 is a negative regulator of progenitor proliferation in adult hippocampal neurogenesis. J Neurosci 26:9703-9712. CrossRef Medline

Islam O, Gong X, Rose-John S, Heese K (2009) Interleukin-6 and neural stem cells: more than gliogenesis. Mol Biol Cell 20:188-199. CrossRef Medline

Kettenmann H, Hanisch UK, Noda M, Verkhratsky A (2011) Physiology of microglia. Physiol Rev 91:461-553. CrossRef Medline

Koo JW, Duman RS (2008) IL-1beta is an essential mediator of the antineurogenic and anhedonic effects of stress. Proc Natl Acad Sci U S A 105:751756. CrossRef Medline

Li L, Walker TL, Zhang Y, Mackay EW, Bartlett PF (2010) Endogenous interferon gamma directly regulates neural precursors in the noninflammatory brain. J Neurosci 30:9038-9050. CrossRef Medline

Lie DC, Song H, Colamarino SA, Ming GL, Gage FH (2004) Neurogenesis in the adult brain: new strategies for central nervous system diseases. Annu Rev Pharmacol Toxicol 44:399-421. CrossRef Medline

Marshall GP 2nd, Demir M, Steindler DA, Laywell ED (2008) Subventricular zone microglia possess a unique capacity for massive in vitro expansion. Glia 56:1799-1808. CrossRef Medline

Miller RJ, Jung H, Bhangoo SK, White FA (2009) Cytokine and chemokine regulation of sensory neuron function. Handb Exp Pharmacol 194:417449. CrossRef Medline

Miron VE, Boyd A, Zhao JW, Yuen TJ, Ruckh JM, Shadrach JL, van Wijngaarden $\mathrm{P}$, Wagers AJ, Williams A, Franklin RJ, ffrench-Constant C (2013) M2 microglia and macrophages drive oligodendrocyte differentiation during CNS remyelination. Nat Neurosci 16:1211-1218. CrossRef Medline

Mohri I, Eguchi N, Suzuki K, Urade Y, Taniike M (2003) Hematopoietic prostaglandin $\mathrm{D}$ synthase is expressed in microglia in the developing postnatal mouse brain. Glia 42:263-274. CrossRef Medline

Monje ML, Toda H, Palmer TD (2003) Inflammatory blockade restores adult hippocampal neurogenesis. Science 302:1760-1765. CrossRef Medline

Monji A, Kato T, Kanba S (2009) Cytokines and schizophrenia: microglia 
hypothesis of schizophrenia. Psychiatry Clin Neurosci 63:257-265. CrossRef Medline

Mosher KI, Andres RH, Fukuhara T, Bieri G, Hasegawa-Moriyama M, He Y, Guzman R, Wyss-Coray T (2012) Neural progenitor cells regulate microglia functions and activity. Nat Neurosci 15:1485-1487. CrossRef Medline

Nakajima K, Kohsaka S (2001) Microglia: activation and their significance in the central nervous system. J Biochem 130:169-175. CrossRef Medline

Nakajima K, Tsuzaki N, Shimojo M, Hamanoue M, Kohsaka S (1992) Microglia isolated from rat brain secrete a urokinase-type plasminogen activator. Brain Res 577:285-292. CrossRef Medline

Nakanishi M, Niidome T, Matsuda S, Akaike A, Kihara T, Sugimoto H (2007) Microglia-derived interleukin-6 and leukaemia inhibitory factor promote astrocytic differentiation of neural stem/progenitor cells. Eur J Neurosci 25:649-658. CrossRef Medline

Nishiyama A, Komitova M, Suzuki R, Zhu X (2009) Polydendrocytes (NG2 cells): multifunctional cells with lineage plasticity. Nat Rev Neurosci 10: 9-22. CrossRef Medline

Oh J, McCloskey MA, Blong CC, Bendickson L, Nilsen-Hamilton M, Sakaguchi DS (2010) Astrocyte-derived interleukin-6 promotes specific neuronal differentiation of neural progenitor cells from adult hippocampus. J Neurosci Res 88:2798-2809. CrossRef Medline

Ortega F, Gascón S, Masserdotti G, Deshpande A, Simon C, Fischer J, Dimou L, Chichung Lie D, Schroeder T, Berninger B (2013) Oligodendrogliogenic and neurogenic adult subependymal zone neural stem cells constitute distinct lineages and exhibit differential responsiveness to Wnt signalling. Nat Cell Biol 15:602-613. CrossRef Medline

Pont-Lezica L, Béchade C, Belarif-Cantaut Y, Pascual O, Bessis A (2011) Physiological roles of microglia during development. J Neurochem 119: 901-908. CrossRef Medline

Reynolds BA, Tetzlaff W, Weiss S (1992) A multipotent EGF-responsive striatal embryonic progenitor cell produces neurons and astrocytes. J Neurosci 12:4565-4574. Medline

Russo I, Barlati S, Bosetti F (2011) Effects of neuroinflammation on the regenerative capacity of brain stem cells. J Neurochem 116:947-956. CrossRef Medline

Schäfers M, Sorkin L (2008) Effect of cytokines on neuronal excitability. Neurosci Lett 437:188-193. CrossRef Medline

Spedding M, Gressens P (2008) Neurotrophins and cytokines in neuronal plasticity. Novartis Found Symp 289:222-233; discussion 233-240. Medline

Spooren A, Kolmus K, Laureys G, Clinckers R, De Keyser J, Haegeman G, Gerlo S (2011) Interleukin-6, a mental cytokine. Brain Res Rev 67:157183. CrossRef Medline

Suzuki SO, Goldman JE (2003) Multiple cell populations in the early postnatal subventricular zone take distinct migratory pathways: a dynamic study of glial and neuronal progenitor migration. J Neurosci 23:42404250. Medline
Temple S (2001) The development of neural stem cells. Nature 414:112117. CrossRef Medline

Thored P, Heldmann U, Gomes-Leal W, Gisler R, Darsalia V, Taneera J, Nygren JM, Jacobsen SE, Ekdahl CT, Kokaia Z, Lindvall O (2009) Longterm accumulation of microglia with proneurogenic phenotype concomitant with persistent neurogenesis in adult subventricular zone after stroke. Glia 57:835-849. CrossRef Medline

Tikka T, Fiebich BL, Goldsteins G, Keinanen R, Koistinaho J (2001) Minocycline, a tetracycline derivative, is neuroprotective against excitotoxicity by inhibiting activation and proliferation of microglia. J Neurosci 21: 2580-2588. Medline

Tremblay ME, Stevens B, Sierra A, Wake H, Bessis A, Nimmerjahn A (2011) The role of microglia in the healthy brain. J Neurosci 31:16064-16069. CrossRef Medline

Vela JM, Molina-Holgado E, Arévalo-Martín A, Almazán G, Guaza C (2002) Interleukin-1 regulates proliferation and differentiation of oligodendrocyte progenitor cells. Mol Cell Neurosci 20:489-502. CrossRef Medline

Vukovic J, Colditz MJ, Blackmore DG, Ruitenberg MJ, Bartlett PF (2012) Microglia modulate hippocampal neural precursor activity in response to exercise and aging. J Neurosci 32:6435-6443. CrossRef Medline

Wagner JP, Black IB, DiCicco-Bloom E (1999) Stimulation of neonatal and adult brain neurogenesis by subcutaneous injection of basic fibroblast growth factor. J Neurosci 19:6006-6016. Medline

Walton NM, Sutter BM, Laywell ED, Levkoff LH, Kearns SM, Marshall GP 2nd, Scheffler B, Steindler DA (2006) Microglia instruct subventricular zone neurogenesis. Glia 54:815-825. CrossRef Medline

Wang X, Fu S, Wang Y, Yu P, Hu J, Gu W, Xu XM, Lu P (2007) Interleukinlbeta mediates proliferation and differentiation of multipotent neural precursor cells through the activation of SAPK/JNK pathway. Mol Cell Neurosci 36:343-354. CrossRef Medline

Wu CH, Wen CY, Shieh JY, Ling EA (1993) A quantitative study of the differentiation of microglial cells in the developing cerebral cortex in rats. J Anat 182:403-413. Medline

Xu J, Ling EA (1994) Studies of the distribution and functional roles of transitory amoeboid microglial cells in developing rat brain using exogenous horseradish peroxidase as a marker. J Hirnforsch 35:103-111. Medline

Zerlin M, Milosevic A, Goldman JE (2004) Glial progenitors of the neonatal subventricular zone differentiate asynchronously, leading to spatial dispersion of glial clones and to the persistence of immature glia in the adult mammalian CNS. Dev Biol 270:200-213. CrossRef Medline

Zhao C, Ling Z, Newman MB, Bhatia A, Carvey PM (2007) TNF-alpha knockout and minocycline treatment attenuates blood-brain barrier leakage in MPTP-treated mice. Neurobiol Dis 26:36-46. CrossRef Medline

Ziv Y, Ron N, Butovsky O, Landa G, Sudai E, Greenberg N, Cohen H, Kipnis J, Schwartz M (2006) Immune cells contribute to the maintenance of neurogenesis and spatial learning abilities in adulthood. Nat Neurosci 9:268-275. CrossRef Medline 